\title{
LA-UR-20-28674
}

Approved for public release; distribution is unlimited.

Title: Microwave Cast Material Examination

Author(s): $\quad$ Imhoff, Seth D.

Luitjohan, Kara Eileen

Lawrence, Samantha Kay

Forsyth, Robert Thomas

Bloom, Rose Anne

Winter, William Paul III

Intended for: Report

Issued:

2020-10-27 
Disclaimer:

Los Alamos National Laboratory, an affirmative action/equal opportunity employer, is operated by Triad National Security, LLC for the National Nuclear Security Administration of U.S. Department of Energy under contract 89233218CNA000001. By approving this article, the publisher recognizes that the U.S. Government retains nonexclusive, royalty-free license to publish or reproduce the published form of this contribution, or to allow others to do so, for U.S. Government purposes. Los Alamos National Laboratory requests that the publisher identify this article as work performed under the auspices of the U.S. Department of Energy. Los Alamos National Laboratory strongly supports academic freedom and a researcher's right to publish; as an institution, however, the Laboratory does not endorse the viewpoint of a publication or guarantee its technical correctness. 


\section{Microwave Cast Material Examination}

Seth D. Imhoff*,1, Kara E. Luitjohan ${ }^{1}$, Samantha K. Lawrence ${ }^{2}$, Robert Forsyth $^{2}$, Rose Bloom ${ }^{2}$, William Winter ${ }^{2}$

${ }^{1}$ Sigma-1, Los Alamos National Laboratory,

M.S. G770, P.O. Box 1663, Los Alamos, NM 87545

2 Sigma-2, Los Alamos National Laboratory,

M.S. G770, P.O. Box 1663, Los Alamos, NM 87545

*Corresponding Author, sdi@1an1.gov
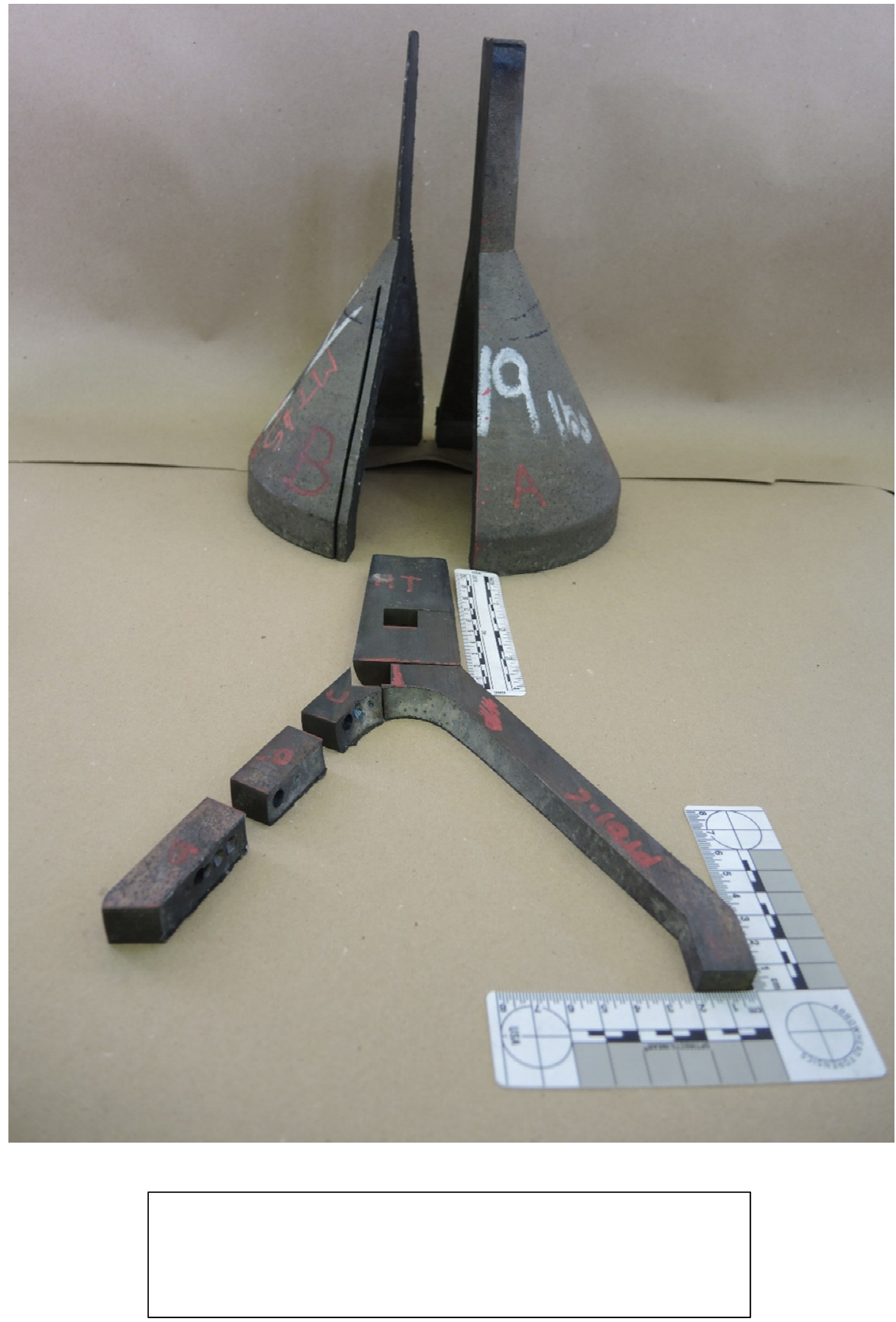


\title{
Microwave Cast Material Examination
}

\author{
Seth D. Imhoff ${ }^{*}$, Kara E. Luitjohan ${ }^{1}$, Samantha K. Lawrence ${ }^{2}$, Robert \\ Forsyth ${ }^{2}$, Rose Bloom², William Winter ${ }^{2}$ \\ ${ }^{1}$ Sigma-1, Los Alamos National Laboratory, \\ M.S. G770, P.O. Box 1663, Los Alamos, NM 87545 \\ 2 Sigma-2, Los Alamos National Laboratory, \\ M.S. G770, P.O. Box 1663, Los Alamos, NM 87545 \\ *Corresponding Author, sdi@lanl.gov
}

\section{Executive Summary}

Microwave-cast material dating from the latest prototype development period and subsequent TRL 7 advancement testing was sent to LANL for additional characterization. The initial characterization described here is considered a supplement to and verification of that performed by Y-12 during the Technology Readiness Assessment process. The carbon chemistry results from Y-12 and LANL regarding early prototype microwave cast test object (CTO) and cylinder castings match within expectations. Only one fully intact as-cast CTO was available for examination in which carbon chemistry does not appear to vary spatially, at least at relatively low carbon levels (hypoeutectic). The large as-cast grain size leads to relatively poor grain size statistics and similar difficulties were encountered during the TRA. Small, isolated gas pores were observed in four of the five metallographic samples in prototype CTO casting PT-01. Finally, the next phase of characterization work, which focuses on corrosion behavior, has started and is described briefly.

\subsection{Introduction and Goals}

Microwave furnace technology is currently being used to cast uranium metal on a prototype and testing basis after achieving TRL7 status with the NNSA [1]. As a result of this continued effort, the advancement of microwave casting technology, equipment design, and operational parameters have matured to a point where material characteristics are expected to be reasonably stable. This stability allows for experimentation which may have a more lasting impact as the concept transitions out of prototype manufacturing.

A detailed study of material cast using microwave technology has been conducted which complements or extends portions of the work performed during the Microwave TRL 7 advancement experiments [2]. The TRL 7 advancement assessed nearly all of the cast test object (CTO) castings that were produced. One of the castings which was not analyzed was sent to LANL for examination. A view of this sectioned CTO is on the front page of this report and again in Figure 1. Additional microwave cast material in the form of pieces or cylinders were also sent to LANL and to LLNL [3] for other forms of analysis. 
This report is meant to add to the body of knowledge regarding microwave cast uranium microstructure and chemistry, and it focuses largely on uranium carbide measurements. Carbon content in uranium is broadly used as a byword for quality, not because it is necessarily the only major controlling factor for properties and performance; instead, carbon is so readily incorporated into uranium as an impurity during processing $[4,5]$ that it may be an indicator of other chemical issues occurring simultaneously.

\subsection{Sample Preparation}

Microstructural analysis was performed on CTO casting PT-01. The cast component was sectioned on a band saw such that the symmetry plane of the conical section could be used for metallographic characterization, visible in Figure 1a, with a total thickness of 0.625 ". Accuracy of the cut is limited by initial setup and blade drift during sawing operations and is within +/- 0.125 " for accuracy of the centerline and thickness variation.

Five locations within the casting were selected for microscopic and chemical evaluation to provide location-specific information. The locations are noted in Figure $1 \mathrm{~b}$, and each section was removed by electro-discharge machining (EDM) with a wire diameter of 0.007 ". The centerline plane of the casting was preserved for metallographic examination, while drill samples for chemistry were taken from other faces of the sections.

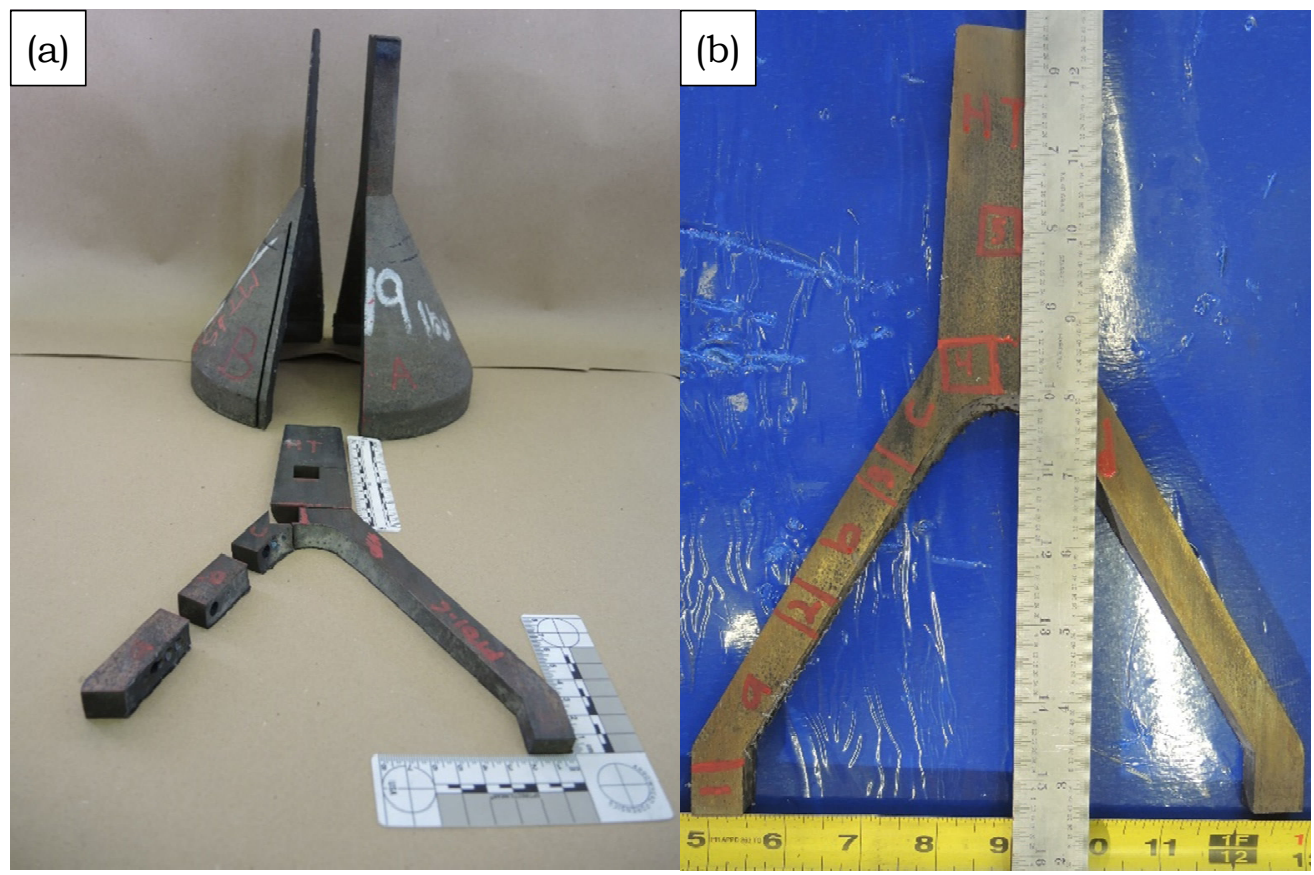

Figure 1: (a) Remnant halves of CTO casting PT-01 above the center slice showing sections removed for further analysis. (b) Locations of each sample section shown on the center slice of the CTO casting prior to removal. 


\section{1) Metallographic Preparation}

The Sigma-2 Characterization Team received the five location-specific numbered samples for metallographic preparation, inclusion analysis, and grain size determination. Sample preparation consisted of mounting, grinding, and polishing the samples. Inclusion analysis consisted of Energy Dispersive Spectroscopy (EDS) and image analysis for inclusion size and distribution.

Samples were mounted in the as-received condition. A cold mounting procedure using Epon $815 \mathrm{C}$ epoxy with Diethylenetriamine (10:1 ratio) followed by overnight curing under pressure ( 1000 psi). All samples were initially ground through a series of decreasingly abrasive steps (Table 1 ) in order to ensure that the sample is planar and that any damaged layers from initial sample preparation are removed.

Table 1: Notes on initial grinding steps for metallographic preparation.

\begin{tabular}{|c|c|c|c|}
\hline Grinding Paper & Lubricant & Platen Speed & Time \\
\hline 120 grit & Water & High & Until planar \\
\hline 320 grit & Water & High & $\sim 1.5$ minutes \\
\hline 600 grit & Water & High & $\sim 2$ minutes \\
\hline 800 grit & Water & Low & $\sim 2$ minutes \\
\hline
\end{tabular}

After grinding, the samples were polished with progressively finer diamond suspensions, and colloidal silica was used for the final polish. A small amount of hydrogen peroxide ( $30 \%$ concentration) was added during the $1 \mu \mathrm{m}$ diamond and colloidal silica polishing steps (see Table 2). Sample polishing was performed on a Struers Tegramin-25 semi-automatic polisher with user-programmed recipes using Struers polishing cloths.

Table 2: General procedure for mechanical polishing of mounted samples.

\begin{tabular}{|c|c|c|c|c|c|}
\hline Suspension & $\begin{array}{c}\text { Polishing } \\
\text { Time }\end{array}$ & Force & $\begin{array}{c}\text { Polishing } \\
\text { Cloth }\end{array}$ & $\begin{array}{c}\text { Platen } \\
\text { Speed }\end{array}$ & $\begin{array}{c}\text { Head } \\
\text { Rotation }\end{array}$ \\
\hline $\begin{array}{c}3 \mu \mathrm{m} \\
\text { diamond }\end{array}$ & 3 minutes & $15 \mathrm{~N}$ & $\mathrm{MOL}$ & $150 \mathrm{RPM}$ & $\begin{array}{c}\text { Counter- } \\
\text { rotation }\end{array}$ \\
\hline $\begin{array}{c}1 \mu \mathrm{m} \\
\text { diamond }\end{array}$ & 3 minutes & $15 \mathrm{~N}$ & $\mathrm{MOL}$ & $150 \mathrm{RPM}$ & $\begin{array}{c}\text { Counter- } \\
\text { rotation }\end{array}$ \\
\hline $\begin{array}{c}1 \mu \mathrm{m} \\
\text { diamond } \\
\mathrm{w} / \mathrm{H}_{2} \mathrm{O}_{2}\end{array}$ & $\begin{array}{c}3.5 \\
\text { minutes }\end{array}$ & $15 \mathrm{~N}$ & $\mathrm{NAP}$ & $120 \mathrm{RPM}$ & Co-rotation \\
\hline $\begin{array}{c}\text { Colloidal } \\
\text { Silica w/ } \\
\mathrm{H}_{2} \mathrm{O}_{2}\end{array}$ & 2 minutes & $20 \mathrm{~N}$ & $\mathrm{NAP}$ & $100 \mathrm{RPM}$ & Co-rotation \\
\hline
\end{tabular}

Note: Steps repeated as necessary to remove scratches.

Prior to imaging in the SEM, the samples were coated in gold to prevent charging of the epoxy. Imaging of samples for inclusion analysis and EDS analysis was performed 
on Thermo-Fisher Helios FIB/SEM using the secondary electron detector. Nine randomly chosen images were taken at 250x for image analysis.

Images were processed using Zeiss AxioVision software and Image $\mathrm{J}$ software to facilitate image analysis. Clemex software was used to perform the actual measurements and analysis.

All images attempting grain size measurements used 50x montages taken in polarized light with a Zeiss AxioObserver running Zeiss AxioVision software. Due to the large size of the grains, and thus unreliable statistics, only qualitative grain size comparisons are provided in this report. The error associated with the measurements have led us to believe that reported numbers would be more misleading than they would be enlightening. In order to ensure that future investigators know what was attempted, the details of the attempts are still outlined here.

Since the electron microscopy was performed prior to attempting grain size measurements, the gold coating was removed and the surface made ready for optical measurements. Table 3 outlines the steps for re-preparation.

Table 3: The progressing of grinding and polishing steps for metallographic re-preparation including process details.

\begin{tabular}{|c|c|c|c|c|c|}
\hline Suspension & $\begin{array}{c}\text { Polishing } \\
\text { Time }\end{array}$ & Force & $\begin{array}{c}\text { Polishing } \\
\text { Cloth }\end{array}$ & Platen Speed & $\begin{array}{c}\text { Head } \\
\text { Rotation }\end{array}$ \\
\hline $\begin{array}{c}3-\mu \mathrm{m} \\
\text { diamond }\end{array}$ & 3 minutes & $15 \mathrm{~N}$ & $\mathrm{MOL}$ & $150 \mathrm{RPM}$ & $\begin{array}{c}\text { Counter- } \\
\text { rotation }\end{array}$ \\
\hline $\begin{array}{c}1-\mu \mathrm{m} \\
\text { diamond }\end{array}$ & 3 minutes & $15 \mathrm{~N}$ & $\mathrm{MOL}$ & $150 \mathrm{RPM}$ & $\begin{array}{c}\text { Counter- } \\
\text { rotation }\end{array}$ \\
\hline $\begin{array}{c}1-\mu \mathrm{m} \\
\text { diamond } \\
\text { w/ } \mathrm{H}_{2} \mathrm{O}_{2}\end{array}$ & $\begin{array}{c}3.5 \\
\text { minutes }\end{array}$ & $15 \mathrm{~N}$ & $\mathrm{NAP}$ & $120 \mathrm{RPM}$ & Co-rotation \\
\hline
\end{tabular}

Note: Steps repeated as necessary to remove scratches.

Two methods were attempted to reveal the grain boundaries: 1.) electropolishing and 2.) etching. Electropolishing was used to remove small scratches that could be left behind after mechanical polishing and to allow the grains to be highly visible in polarized light. Table 4 outlines the electropolishing parameters. While specific regions of interest were revealed in detail after electropolishing, attaining a large area from which proper statistics could be generated proved difficult in light of the large grain size.

Etching was also attempted in order to make the grain boundaries more visible. The samples were etched with $10 \%$ Oxalic acid using 6 VDC and $30<1$ second pulses. Severe etch pitting occurred at the edge of the samples. Results were variable from sample to sample and edge boundaries were not revealed by the etching process. 
Table 4: Electropolishing details.

\begin{tabular}{|c|c|c|}
\hline $\begin{array}{c}\text { Electropolish } \\
\text { Solution }\end{array}$ & $\begin{array}{c}\text { Voltage } \\
\text { Applied }\end{array}$ & $\begin{array}{c}\text { Time Voltage Applied } \\
\text { 45\% Ethanol }\end{array}$ \\
$\begin{array}{c}27.5 \% \text { Ethylene Glycol } \\
27.5 \% \text { Phosphoric } \\
\text { Acid }\end{array}$ & 10 VDC & $\begin{array}{c}\text { 2 Minutes Total } \\
\text { (Note: Samples polished for 30 seconds, } \\
\text { rotated 180 } \text {, and polished an additional } 30 \\
\text { seconds. This process was repeated for } 2 \\
\text { minutes. The samples were rinsed in water } \\
\text { and isopropanol and dipped in the }\end{array}$ \\
$\begin{array}{c}\text { (Note: Electropolish } \\
\text { solution stirred for } \\
\text { entire process) }\end{array}$ & $\begin{array}{c}\text { electropolish solution (no voltage applied) for } \\
15 \mathrm{sec} \text { and rinsed with water and } \\
\text { isopropanol.) }\end{array}$ \\
\hline
\end{tabular}

2.2) Carbon Analysis

Some spatial variation is generally expected when measuring chemistry; therefore, during a detailed analysis, sampling multiple locations is very important. The five metallographic samples from PT-01 (as indicated with numeric labels in Figure 1) were sampled on the back-side of the sample cube face relative to the metallographic plane. Alphabetically identified samples $(a, b, c)$ were used to measure the inside and outside surface chemistry of the casting as a function of vertical position. Drill samples were taken in the approximate vertical-middle of each section.

All drilled chips were removed without any coolant or cutting fluid with a $1 / 8$ " diameter bit using a slow spindle rotation speed $(80 \mathrm{rpm})$. The load on the bit is applied manually, whereby the operator increases downward force slowly until a "pigtail" is generated at each drill flute. It should be noted that the samples tested here are mainly from relatively low carbon content materials. The individual turnings tend to fracture during cutting as the carbon content increases, resulting in a less coherent "pigtail" or simply small chips. Special attention is paid to spark generation or visible damage to the bit, and would have, if observed, resulted in the chips generated being removed as waste. Sparking or bit erosion would indicate potential contamination of the sample from the drill bit.

Carbon content of the chip samples was measured using a LECO CS 844 carbon/sulfur analyzer following a standard procedure. Under the basic procedure, five blank samples are first run in order to obtain an accurate background measurement. The machine is then calibrated using a variety of standards. For the results presented here, the machine was calibrated for carbon values between 1370 and $40 \mathrm{wppm}$. After a calibration check is performed, the samples are then ready for analysis. All samples are placed in a ceramic crucible along with $\sim 1 \mathrm{~g}$ of accelerator material LECOCEL II HP, a coarse tungsten and tin powder. At least six replicates per sample with varying weights were analyzed. The weights of the replicates ranged from 1.058 to $0.1964 \mathrm{~g}$. The majority of the samples used crucibles that were prebaked at $900^{\circ} \mathrm{C}$ for at least 40 min except for the PT01 samples which used fresh crucibles.

Once the sample mass is weighed and recorded, the crucible is loaded into the furnace of the instrument. After the machine purges the furnace with oxygen to clear out any 
$\sum$ Foundry and Solidification Science Team

Los Alamos National Laboratory

residual atmospheric gases, the induction furnace is turned on. The high frequency field couples with the inductive elements of the chip samples and the accelerator material generating heat. This combined with a high oxygen atmosphere causes the sample to combust. Any carbon within the sample is released to combine with oxygen to form $\mathrm{CO}$ or $\mathrm{CO}_{2}$. After converting $\mathrm{CO}$ to $\mathrm{CO}_{2}$ by flowing through a catalyst, the gas is detected by a pair of non-dispersive infrared (NDIR) cells and output to the user as wt\% carbon.

\subsection{Results}

\subsection{Common Features}

In all locations throughout the PT01 casting, the overall grain structure is typical for as-cast uranium of relatively high purity. It is important to acquaint the reader with several recurring features that are visible in cast uranium microstructures since, to a non-expert, there may appear to be no qualitative difference between different sections or even different castings of relatively pure uranium.

Figure 2 is a small subsection of an optical image taken in polarized light, hence the rather extreme color palette when compared to the silvery color of freshly polished uranium seen in normal ambient light. Uranium grains are three dimensional structures with boundaries between neighboring grains and any particular micrograph is a $2 \mathrm{D}$ slice through the set of grains. The grains are distinguished by their crystallographic orientation in space. The metallographic preparation and the use of polarized light will tend to make different grains relatively easy to distinguish by eye since they appear as different colors. The example micrograph exhibits several of the features which will be discussed in more depth. 


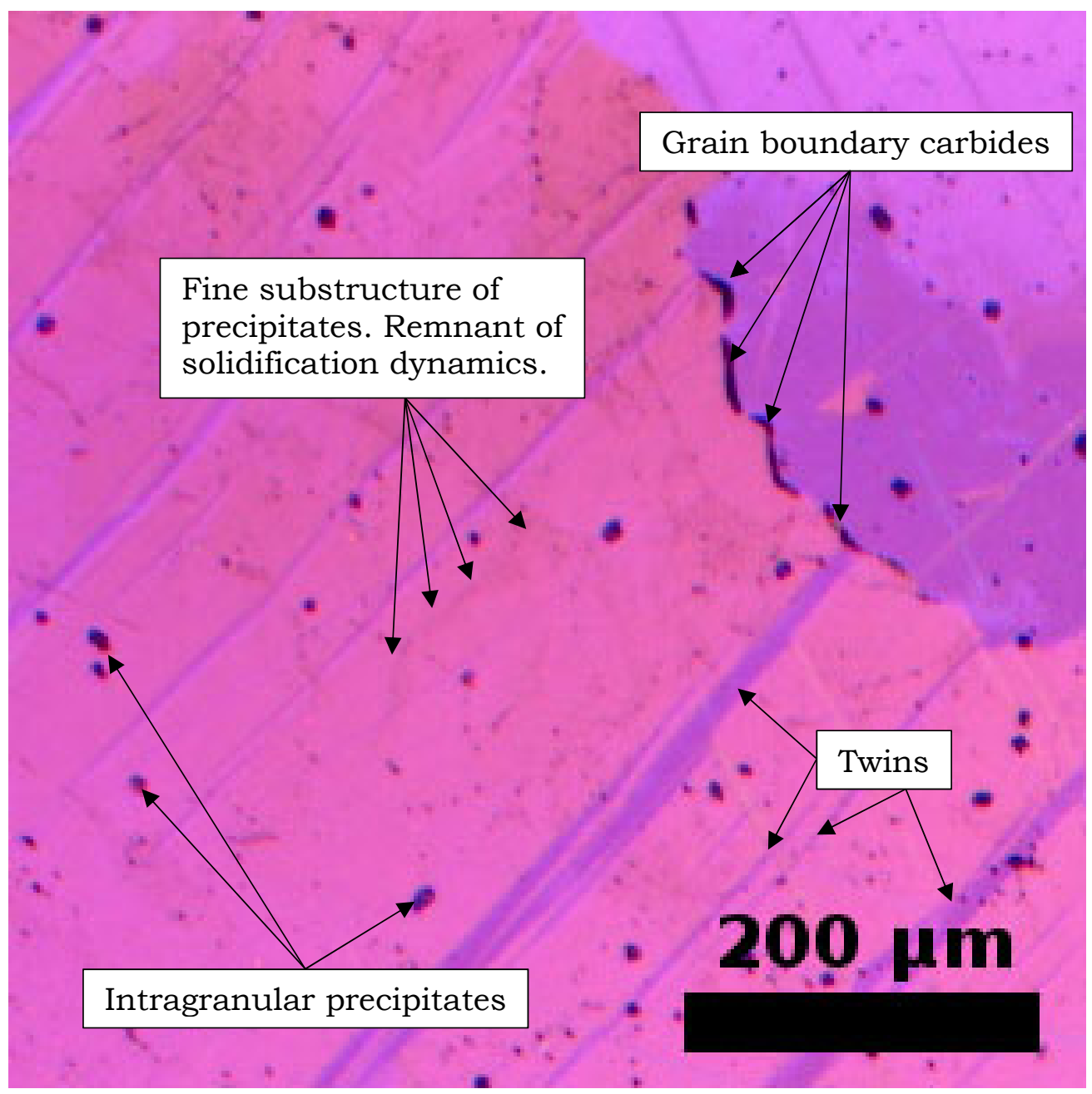

Figure 2: An annotated and expanded section of an optical micrograph from PTO1-section4 showing some prominent microstructural features. Intragranular and grain boundary carbides show as nearly-black particles. The fine substructure manifests as strings of faint contrast. Crystallographic differences are highlighted in the polarized light. Therefore, different grains or crystallographic twins within one grain will photograph with distinct color differences.

Crystallographic twinning is essentially a pair of planar defects in a crystal which results from a growth defect or as a slip mechanism during plastic deformation. The result of a twin will be a region where atoms in the parent crystal and in the twin have different orientations. In the annotated Figure 2, this difference in orientation results in the color differences. In alpha-phase uranium, twins play an important role in plastic deformation response and are common in cast uranium because of intergranular stresses that arise from shrinkage and transformations during cooling.

Due to the most common processing steps involved in uranium refinement and metallurgy, uranium oxy-carbo-nitrides, $\mathrm{U}(\mathrm{OCN})$, of varying compositions tend to be the most common inclusion in cast uranium. Uranium carbide often takes the most prominent role in terms of volume fraction or dominant chemistry. These precipitates may manifest in several ways in cast uranium and are best characterized by their source rather than any particular features identifiable in images. Agglomerates and large inclusions will tend to have formed in the otherwise molten uranium. None of 
these agglomerates are observed in Figure 2. U(OCN) that may precipitate relatively early in the cooling and solidification process appear as faceted crystals inside of grains. Crystals present at grain boundaries may be isolated or show up as layers. The grain boundaries may have been slightly higher in carbon content due to microsegregation, or the faster diffusive transport along the grain boundaries may have simply allowed for faster continuous growth well into the solid state regime. Finally, carbon that was either solubilized in the solid uranium at high temperature or intercellular regions may present as very small precipitates.

Quantitative analysis in this report will focus on inclusion analysis (composition, volume fraction, number density, and distribution of sizes) and total carbon content.

\subsection{Energy Dispersive Spectroscopy of Inclusions}

The most common inclusions in relatively pure cast uranium are typically $\mathrm{U}(\mathrm{OCN})$ crystals. The mechanism for formation may differ for each individual particle and that mechanism may be influenced by total $\mathrm{O}, \mathrm{C}$ and $\mathrm{N}$ available and the ratios that are present in the starting material.

Mounted and prepared samples were gold coated to prevent charging of the epoxy mount from the electron beam of the Thermo-Fisher Helios FIB/SEM used for EDS analysis. Each sample was imaged at 500x, and an EDS map was collected to show concentrations of elements. The specific elements mapped were carbon (C), nitrogen $(\mathrm{N})$, oxygen $(\mathrm{O})$, uranium $(\mathrm{U})$, silicon $(\mathrm{Si})$, and aluminum (Al). Overall, t it was difficult to determine if a specified element was present within the inclusions using the EDS maps. A map taken at a higher magnification may be more useful in the future (See Figure 3). Due to limitations with EDS in accurately quantifying light elements, the EDS analysis performed was qualitative rather than quantitative. Any weight percent listed are not used for quantitative analysis but rather as an indicator of the presence of an element.

Regardless of the limitations of EDS mapping, it is particularly useful for distinguishing dominant elements in particular cases. For instance, in Figure 3 an elongated inclusion, which may appear indistinguishable in optical microscopy, will appear with a distinct contrast using backscattered electron microscopy. Furthermore, EDS shows that oxygen is present in the elongated inclusion to a higher degree than the faceted (darker) carbide particles.

In addition to the EDS mapping of each sample, EDS line scans were performed on a few inclusions from each sample. The majority of the inclusions had a spatially raised portion within the boundaries of the inclusion. The line scans on these inclusions revealed that the lower part of the inclusion was most often carbon rich, while the raised portion of the inclusion tended to be nitrogen rich (See Figure 4). Line scans on the inclusions with shallow cavities and dark precipitates within the raised portion of the inclusions, Figure 5, were oxygen rich. On the precipitates along the grain boundaries, a small oxygen peak was detected during the line scans such as that in Figure 6. In comparing the EDS line scan data and the EDS map data between the samples, no significant chemistry differences could be determined from sample to sample. 
$\sum \begin{aligned} & \text { Foundry and Solidification Science Team } \\ & \text { Los Alamos National Laboratory }\end{aligned}$

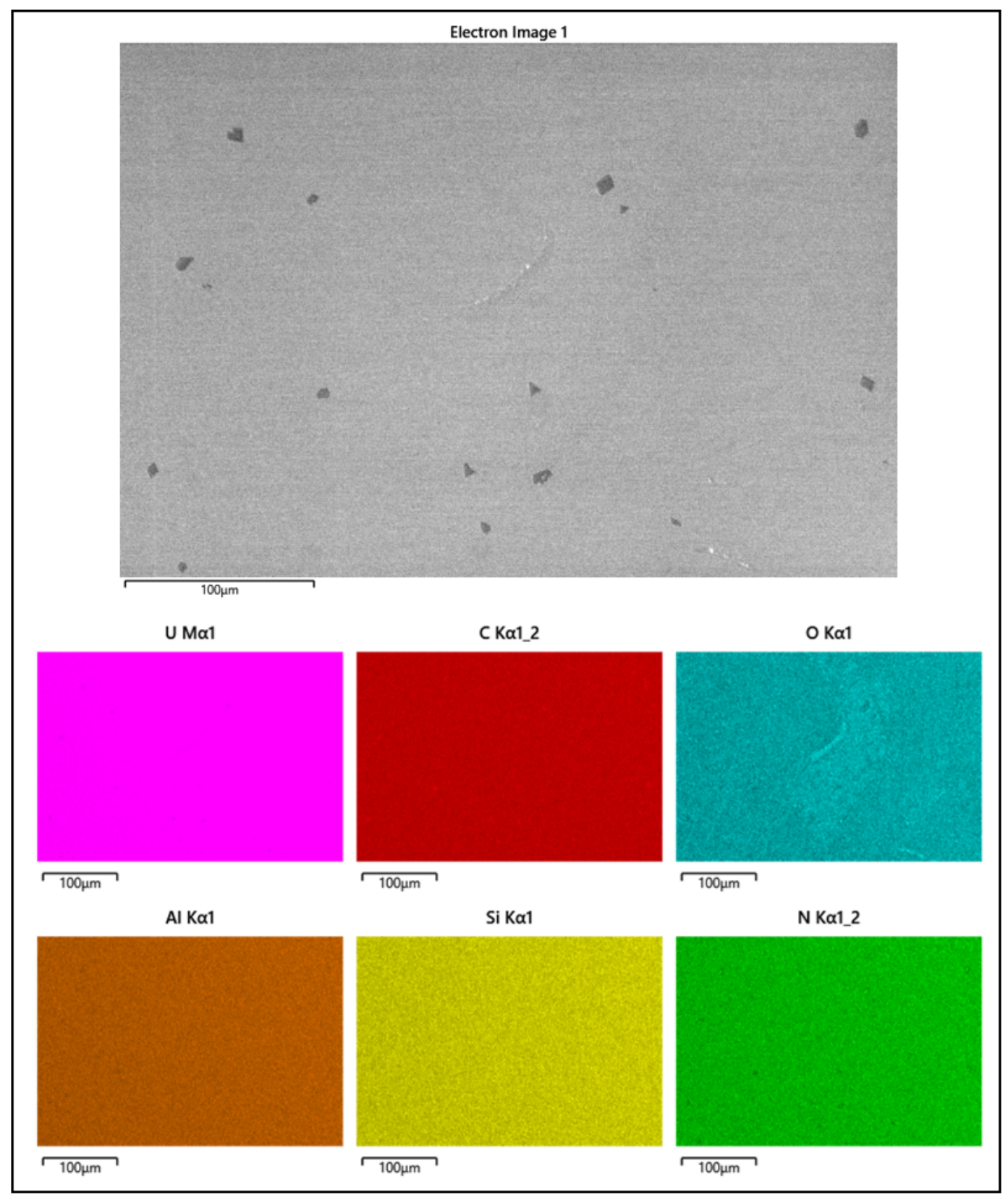

Figure 3: 500x image and associated EDS maps. Note the elongated oxygen rich precipitate in the center of the main micrograph which is highly visible in the oxygen (O Ka1) EDS map. 


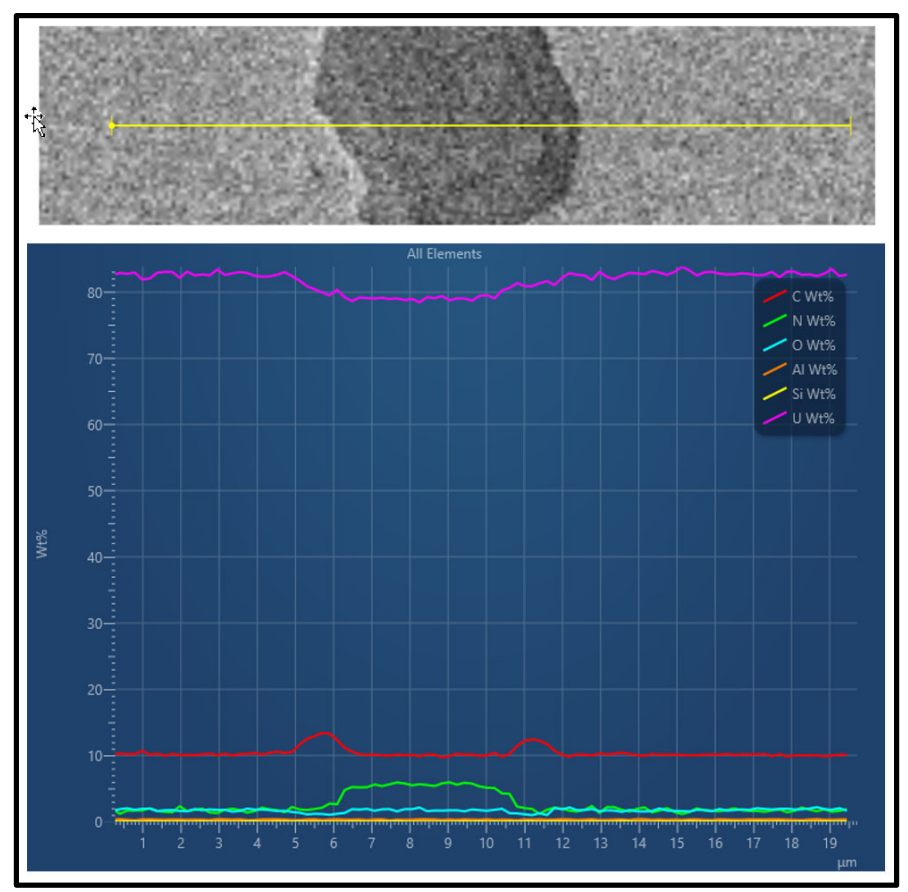

Figure 4: EDS line scan across a typical inclusion. Note the carbon peaks (red) that correspond with the edges of the inclusion and the nitrogen peak (green) that corresponds to the raised portion of the inclusion.

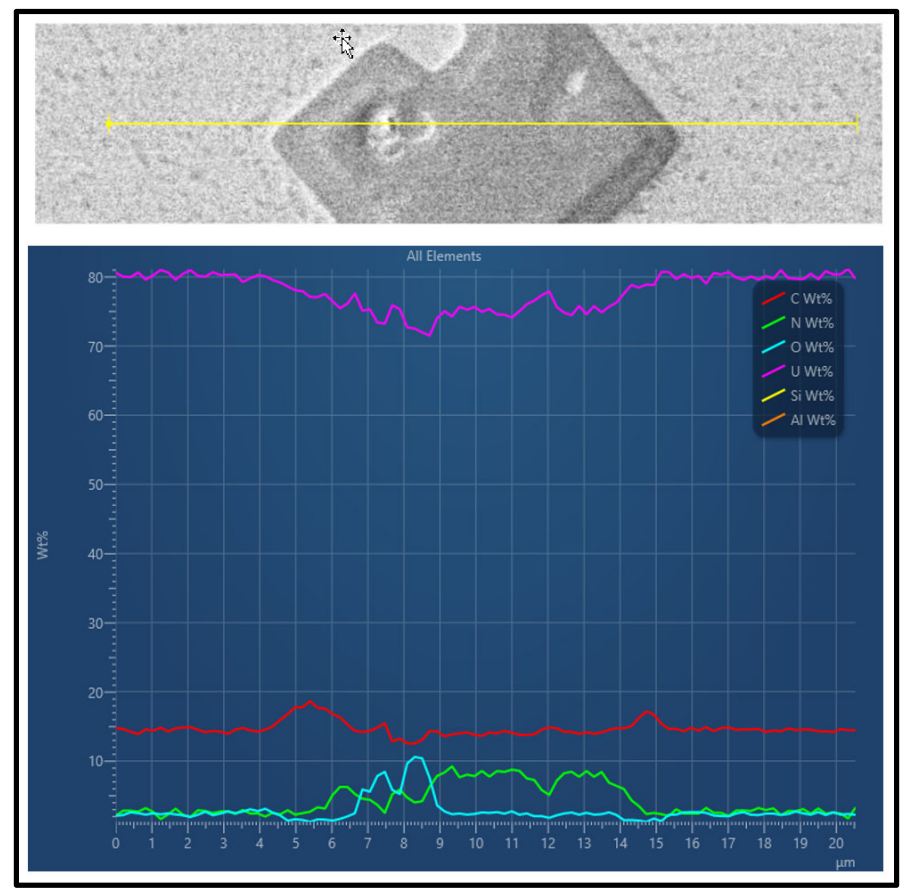

Figure 5: EDS line scan across an inclusion with the dark precipitate in a shallow cavity. Note the carbon peaks (red) that correspond with the edges of the inclusion and the nitrogen peak (green) that corresponds to the raised portion of the inclusion. The oxygen peak (light blue) corresponds with the dark precipitate within the shallow cavity. 


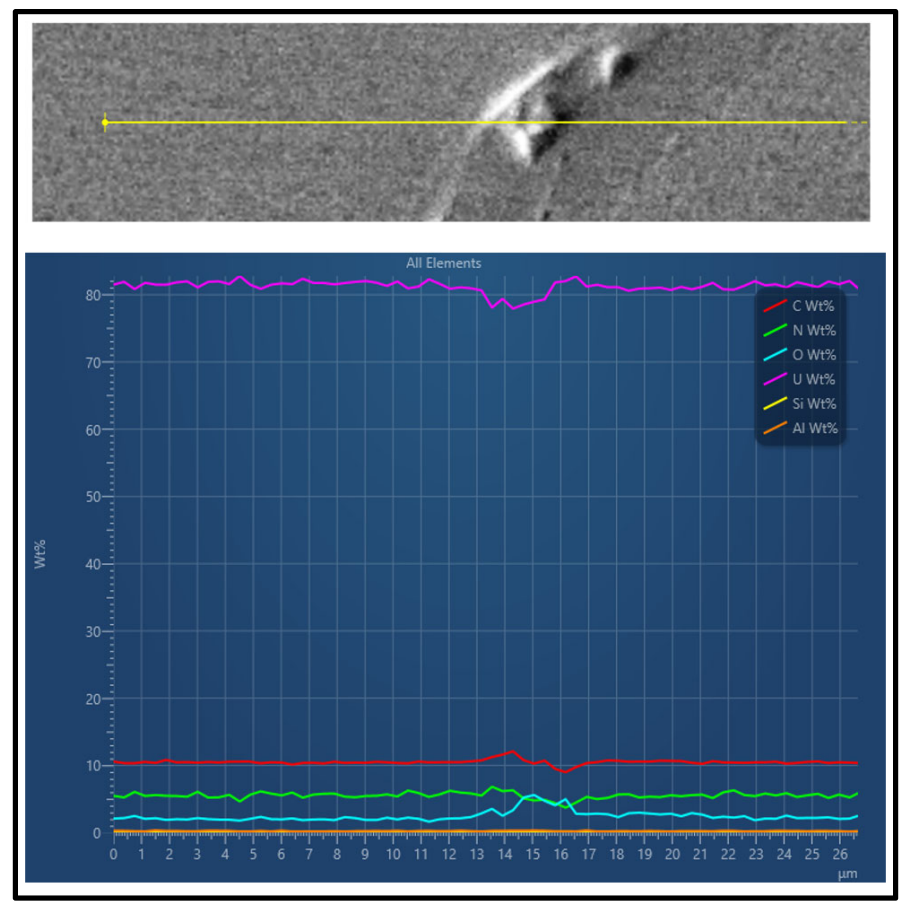

Figure 6: EDS line scan across an elongated precipitate along the edge of a grain boundary. Note the small oxygen peak (light blue) that corresponds to the raised portion of the precipitate.

\subsection{Number density, size, and volume fraction}

The overall character of inclusions does not change significantly with location inside the casting, but there are some relatively weak trends that are worth noting. The number density of carbide particles appears to fall as a function of vertical height within the casting. The individual particle size increased slightly with vertical height. Since these values are operating in opposing directions, the constant or near constant volume fraction is consistent with the collected microstructural data.

The volume percent of phases can be accurately calculated by the area percent of phases in 2D slices (micrographs). The trend with section number (in order of vertical position) are provided in Figure 7 a where it reasonable to assume that the values are constant within sampling error $(0.34 \%+/-0.07)$. That said, Section C4 appears to have a larger volume fraction than the others. Statistical analysis of variance [6] shows that section C3 is just outside of the semi-arbitrary $95 \%$ confidence range for it to statistically match the other mean values. A Tukey multiple pairwise comparison $[7,8]$ shows that only the lowest individual section $\mathrm{C} 1$ paired with $\mathrm{C} 4$ lies outside of the $95 \%$ confidence interval. While it is still reasonable to treat the collection of data as having the same mean volume fraction, this is an indication that there may be a weakly increasing volume fraction with vertical height. Any declaration of a true trend would be marginal.

A true particle size description is not accurately obtained through 2D slice analysis, but general trends are reliable. The particle size inaccuracy is due to simple topology. As an example, if there are a collection of randomly arranged spheres of exactly the same size, any 2D slice through those spheres would reveal circular diameters ranging from the actual diameter of the spheres to an infinitesimally small circle that is the 
slice through the very top or bottom. There are topological correction factors which can be applied quite accurately when quantitative information must result from this type of $2 \mathrm{D}$ analysis, but it requires additional information regarding particle shapes in three dimensions. Regardless, the average observed dimension will be seen to increase even without a correction scheme when the actual particles are larger in an area. In this report, no attempt is made to determine true three dimensional sizes and apparent particle size is used to determine if there are differences between regions.

Crystals that precipitate from the liquid phase as isolated particles, tend to have a size distribution that is described well by a lognormal distribution. While there is no single underlying mechanism that demands a lognormal distribution, there are two reasons for this: 1.) Any real particle cannot be less than or equal to zero in size. 2.) Most particles will be small and only those which nucleate early will have grown significantly (in the absence of significant coarsening) giving a long tail to the distribution. Therefore, the log-mean value is plotted in Figure $7 \mathrm{~b}$.

Finally, the number density is accurate by this method with some limiting cases. The number density of $\mathrm{U}(\mathrm{C}, \mathrm{N}, \mathrm{O})$ particles appears to fall as a function of vertical height within the casting, Figure 7c. When taken as a group, there are some weak variations which do appear to be driven by location within the casting.
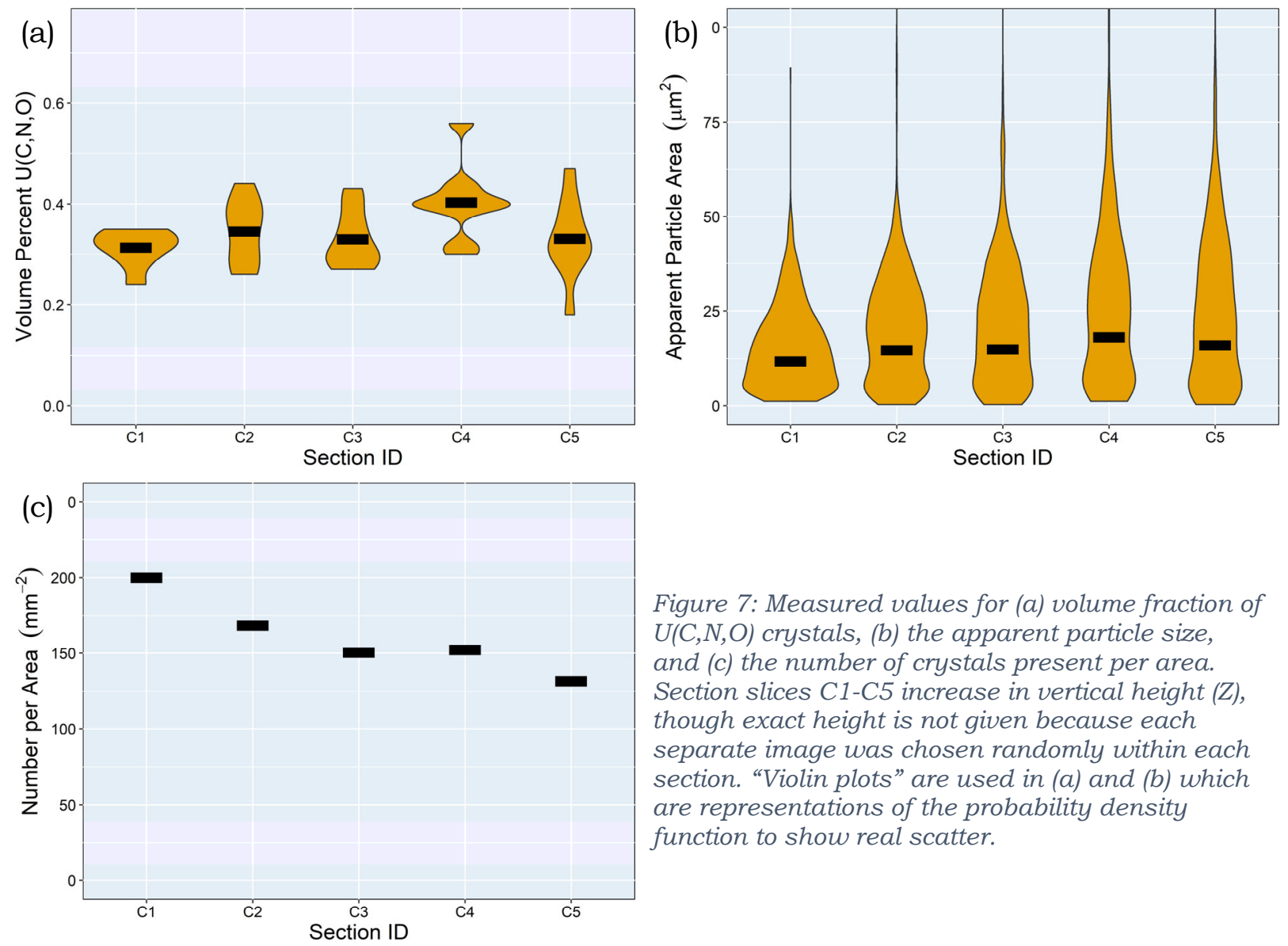

Figure 7: Measured values for (a) volume fraction of $U(C, N, O)$ crystals, (b) the apparent particle size, and (c) the number of crystals present per area. Section slices C1-C5 increase in vertical height (Z), though exact height is not given because each separate image was chosen randomly within each section. "Violin plots" are used in (a) and (b) which are representations of the probability density function to show real scatter. 


\subsection{Carbon Content by Interstitial Analysis}

Chemical sampling, cleaning, and analysis methods tend to strongly affect chemical determinations; calling into question single sample testing and encouraging roundrobin type experiments where multiple independent entities compare results.

Based upon the most recent 811 carbon analysis trials conducted by Sigma-1, when our record keeping method changed to allow for easier variable separation, the distribution of deviations is found to be normally distributed within the first standard deviation with deviations from normal on the positive side of the mean. The positive skew is primarily due to the fact that measurements are inherently non-negative and most samples that are being measured tend to be relatively pure materials. A secondary qualitative (but significant) reason for the skewness is that method variability (e.g. unremoved contaminants) would tend to increase the measured carbon level.

In Sigma-1 it has been found that occasional outliers tend to be significantly positive when they occur. While the specific mechanism for this large positive and occasional deviation has not yet been identified, it appears to be reasonable that they be treated as true outliers and not as critical extreme features. Since the distributions of measurements are included in this report and noise is readily identifiable, the high outlier values have been retained. One very simple way of understanding the context of a numerical result for chemistry is to plot the distributions along with the mean and the median of the samples.

Figure 8 plots each microwave cast piece along with a visual representation of the probability density (filled "violin" plots) as well as the average (blue squares) the median (red circles), and Y-12 measured average where available (black diamonds). It is observed that all LANL-made measurements match those of Y-12, with only one sample being noticeably different in average quantity. The difference observed for 3K74-7F-TR15 still falls within a typical range of measurements so it is not considered a major concern at this point. Therefore, we believe that there is good confidence that both LANL and Y-12 methods, while they may differ in some details, provide the same information within reasonable bounds of accuracy. Furthermore, there is additional confidence in measurements made only at one of the sites.

Casting PT01 was sampled for carbon chemical analysis on the opposite side of the section used for imaging, providing as close of a sampling match as possible. The resulting carbon content per section, identified by vertical distance from the bottom of the casting, is summarized in Figure 9.

Since there is already a significant amount of information from the PT01 casting relative to inclusions, it provides an additional check on chemical analysis carried out by combustion (LECO measurements). In short, the use of image analysis for chemistry is the following: calculate the volume fraction of the micrographs occupied by uranium carbide particles. Using an assumed carbide chemistry as well as the known densities and molar weights of uranium, uranium carbide, and carbon, the total carbon content can be expressed as wppm. 


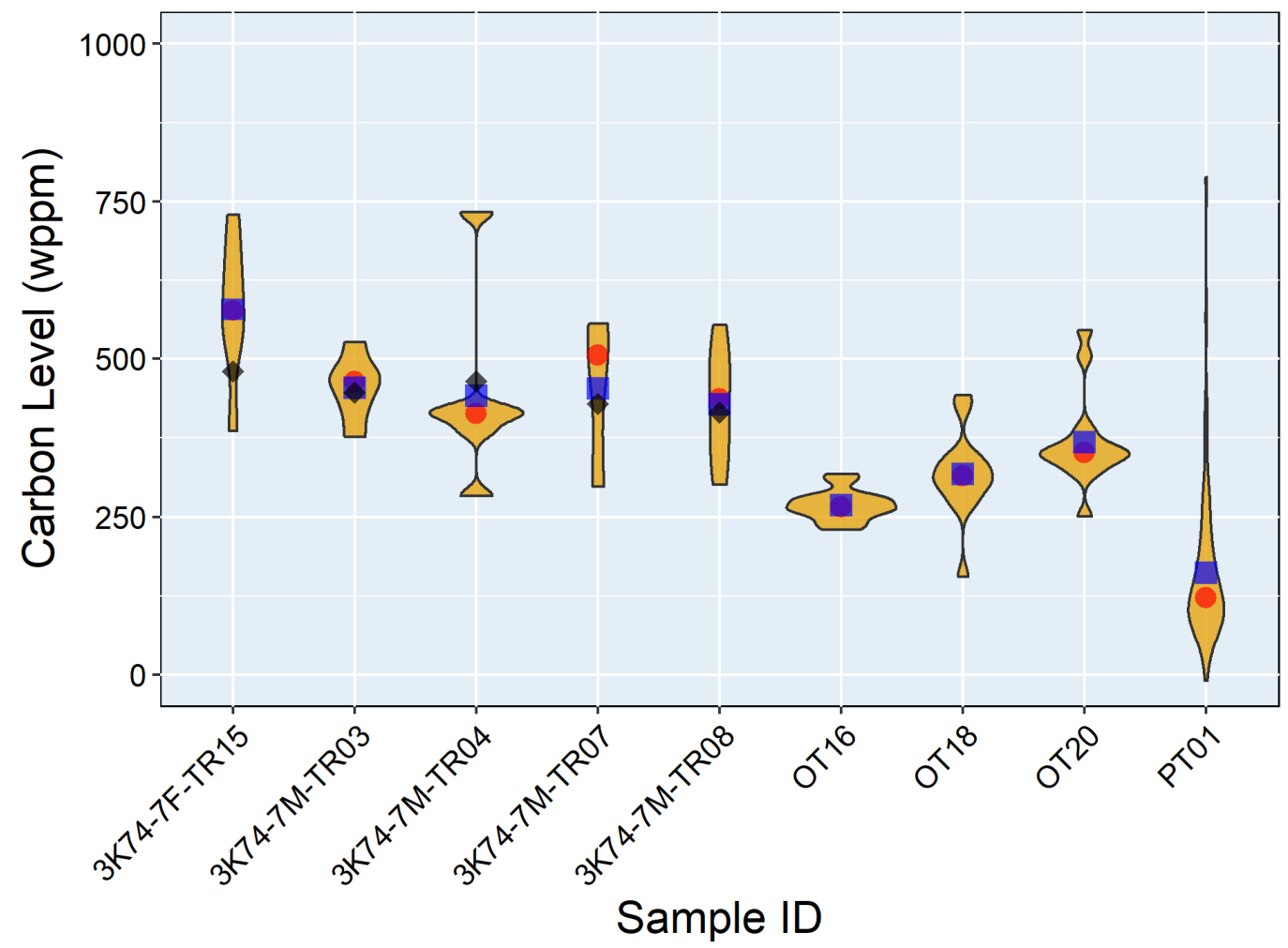

Figure 8: Carbon content measurements from all of the castings sampled for this study (not location specific). All IDs starting in $3 K 74$ used the same lot of initial charge material. Red circles indicate the median for each set, blue squares are the mean value, and black diamonds are average values measured at Y-12.

Carbon composition that is derived from image analysis, because of some assumptions and imaging limitations, have at least two potentially major sources of error acting in different directions. First, the values only account for carbon that is present directly in the portion of the carbide distribution that is sampled (particle censoring). Therefore, it cannot interpret any solubilized carbon in the uranium and will generally not be able to capture information from fine precipitates in intercellular regions. On the other hand, unless a large amount of individual particle analysis can give high quality statistics relating to the $\mathrm{C} / \mathrm{O} / \mathrm{N}$ ratios across all of the inclusions, an assumption of UC would lead to over estimation of carbon. It is somewhat serendipitous then that image analysis results in a total carbon concentration of $118 \mathrm{wppm}$ while the median value (to eliminate effects of outliers) of the LECO technique gives $122 \mathrm{wppm}$.

Sampling of the volumes between metallographic sections allowed for chip samples to be extracted from the interior and exterior of the casting. When sampling for bulk properties, surface chip samples are typically not used because of potential surface effects, however, in this case the investigators were attempting determine if there were any differences directly related to the surfaces. Interior and exterior chip samples are identified and the carbon chemistry results summarized by Figure 10.

Taken as a whole, as in Figure 11, it is clear that there is little or no systematic variation in carbon chemistry from the bottom to top or for the interior vs exterior of the casting. 

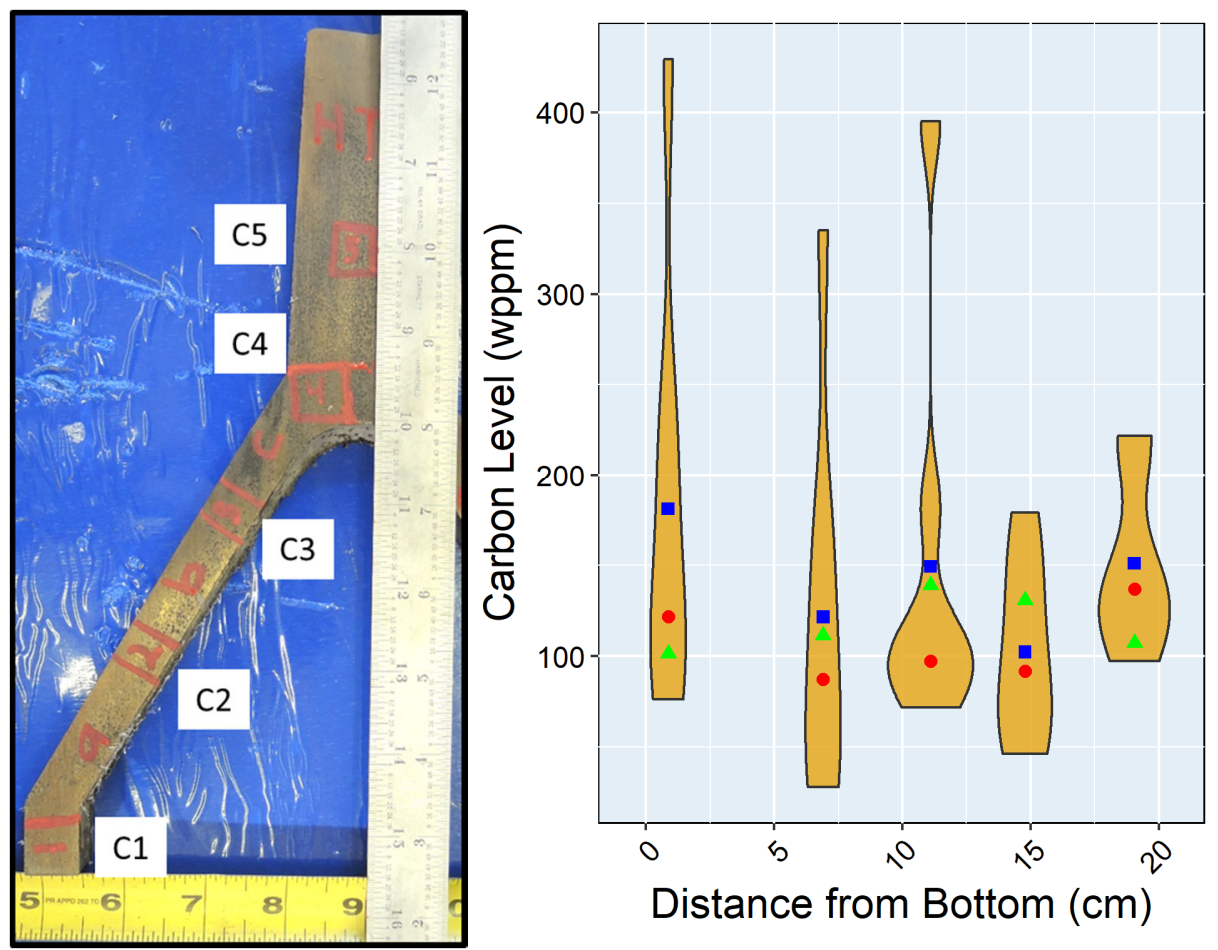

Figure 9: Sections C1 through C5 shown spatially (left) with the measured carbon content graphed (right). Drill samples were taken on the back face, as shown, of each section. Blue squares indicate the mean and red circles indicate the median. Green triangles are the carbon values as determined from image analysis.
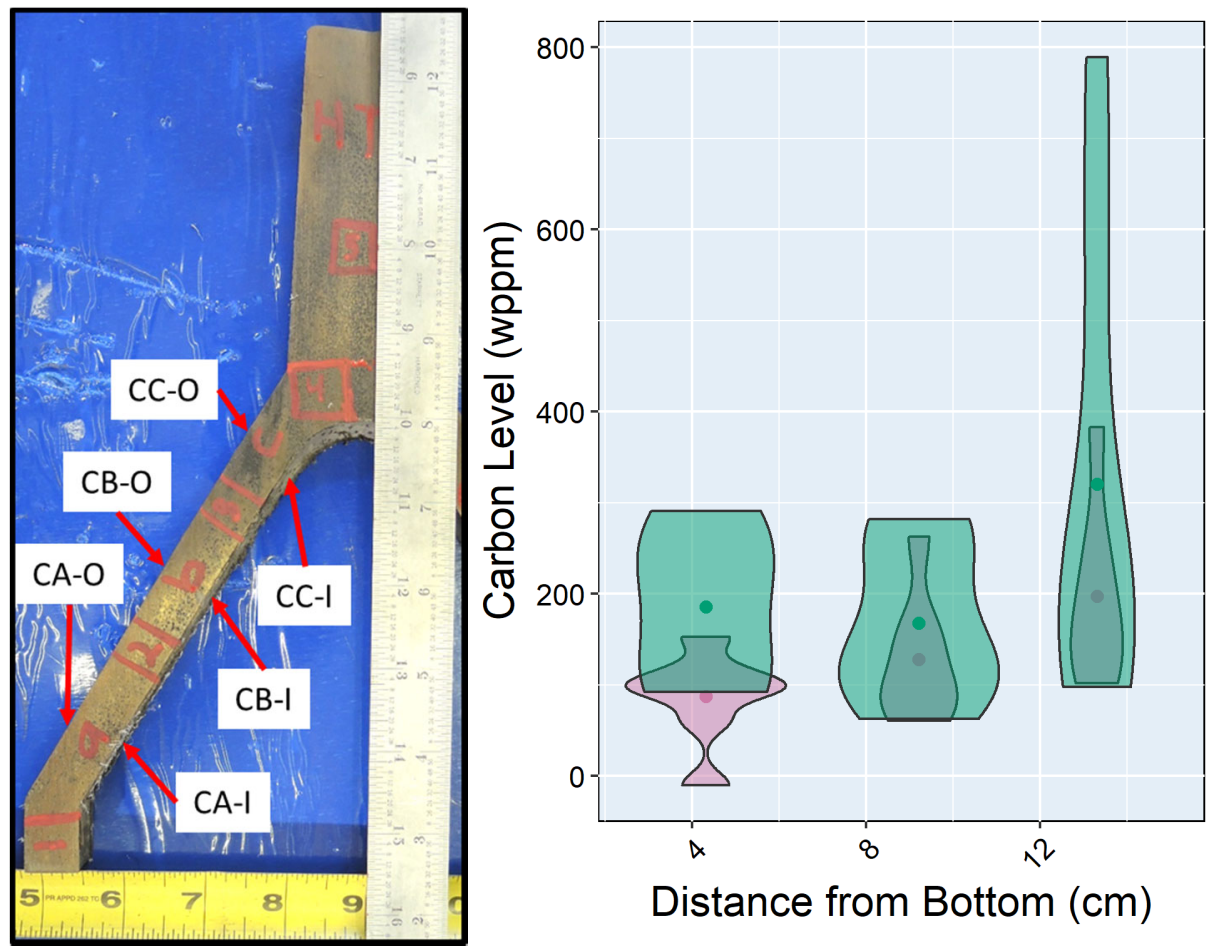

Figure 10: Locations and labels for chemistry samples taken from the inner (pink) and outer (green) surfaces of the casting plotted as an approximate function of vertical height. Circular points indicate the mean value. 


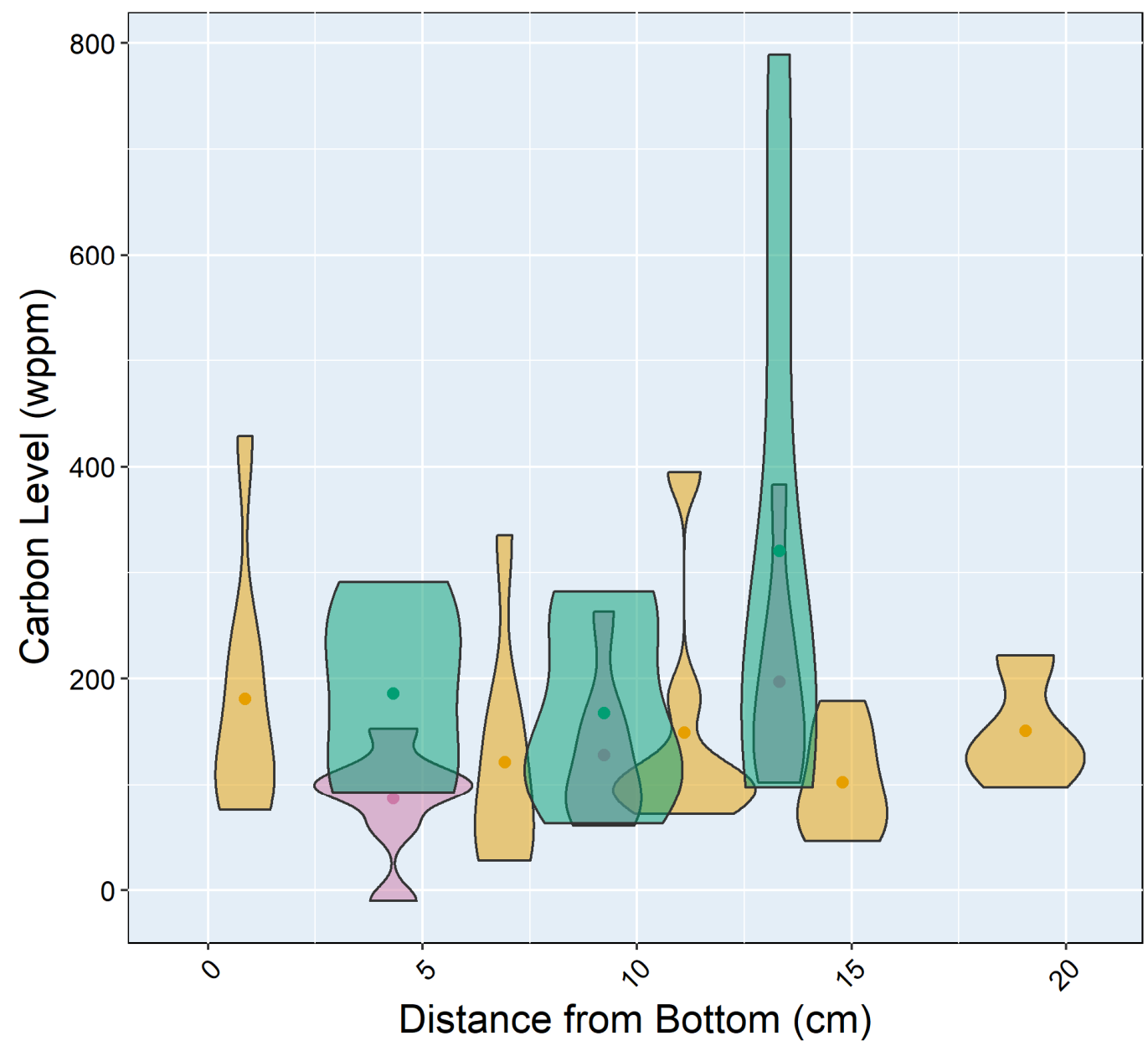

Figure 11: Carbon content for all sample locations plotted as a function of approximate vertical distance from the bottom of the casting. Points represent the mean value of each sample set. Taken as a set, there is little or no indication of a statistically significant difference of carbon content as a function of vertical position or from the inner (pink), bulk (orange), or outer (green) portions of the casting.

\subsection{Comments on Grain Size and Section Images}

Very large, elongated, and irregular shaped grains with small grains interspersed among the large grains were observed in all samples. In addition to the large grains, heavy twinning was observed within the grains in all samples. Due to inconsistent sample preparation results, it was difficult to make a good comparison between samples in regards to degree of elongation of grains. A better sample preparation method is needed for grain size analysis, and development of a different preparation method is planned for the near future.Additionally, a comparison will be made between samples to determine if any differences in grain size exist based on sample location within the casting.

Figure 12 through Figure 16 show the entire cross section of the CTO casting at each location, 1 through 5. Qualitatively, the morphologies of all regions are dominated by large and elongated grains. It is likely that the smaller grains are an artifact from the 2D nature of optical microscopy and are sections from other large columnar grains. Sections C4 and C5 show the least degree of directionality in their grain structure, 
which may be due to the fact that they were taken adjacent to and within the riser (aka. lug or hot top) section of the casting. The slower solidification rate experienced by the larger cross-section (and highest initial temperature) riser is the most likely area for columnar growth to give way to an equiaxed structure.

In all sections there were at least some indications of porosity. The circular cross sections and small total volume of the pores may indicate gas bubbles. There is no indication of feeding porosity or large-scale shrinkage cavities. Feeding porosity would be unexpected in pure uranium as it tends to be more problematic in alloys with large freezing ranges. The fact that there were no large shrinkage cavities is an indication that the thermal profile within the mold was appropriate.

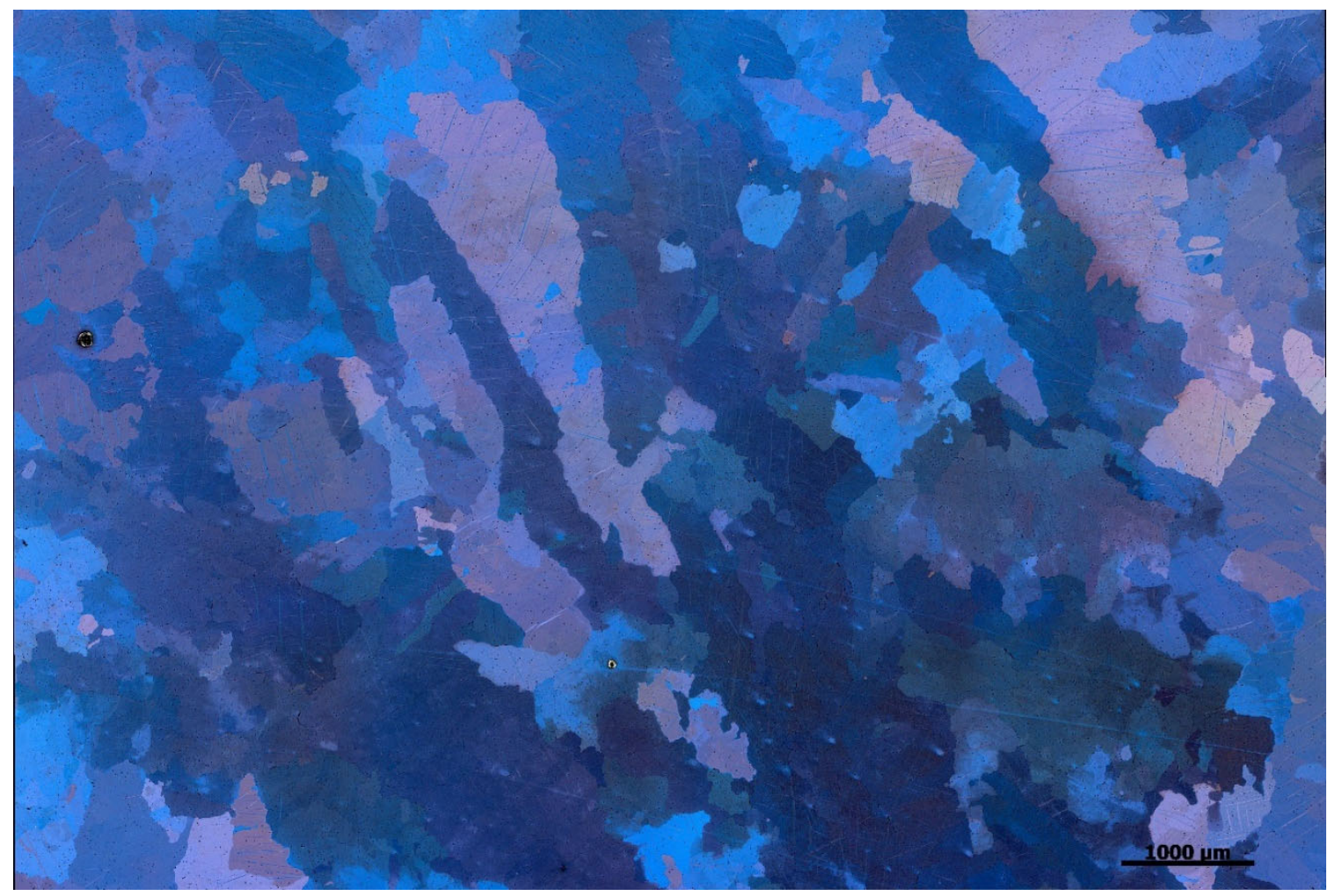

Figure 12: Montage image (each 50x) of section C1. 


\section{$\sum$ Foundry and Solidification Science Team Los Alamos National Laboratory}

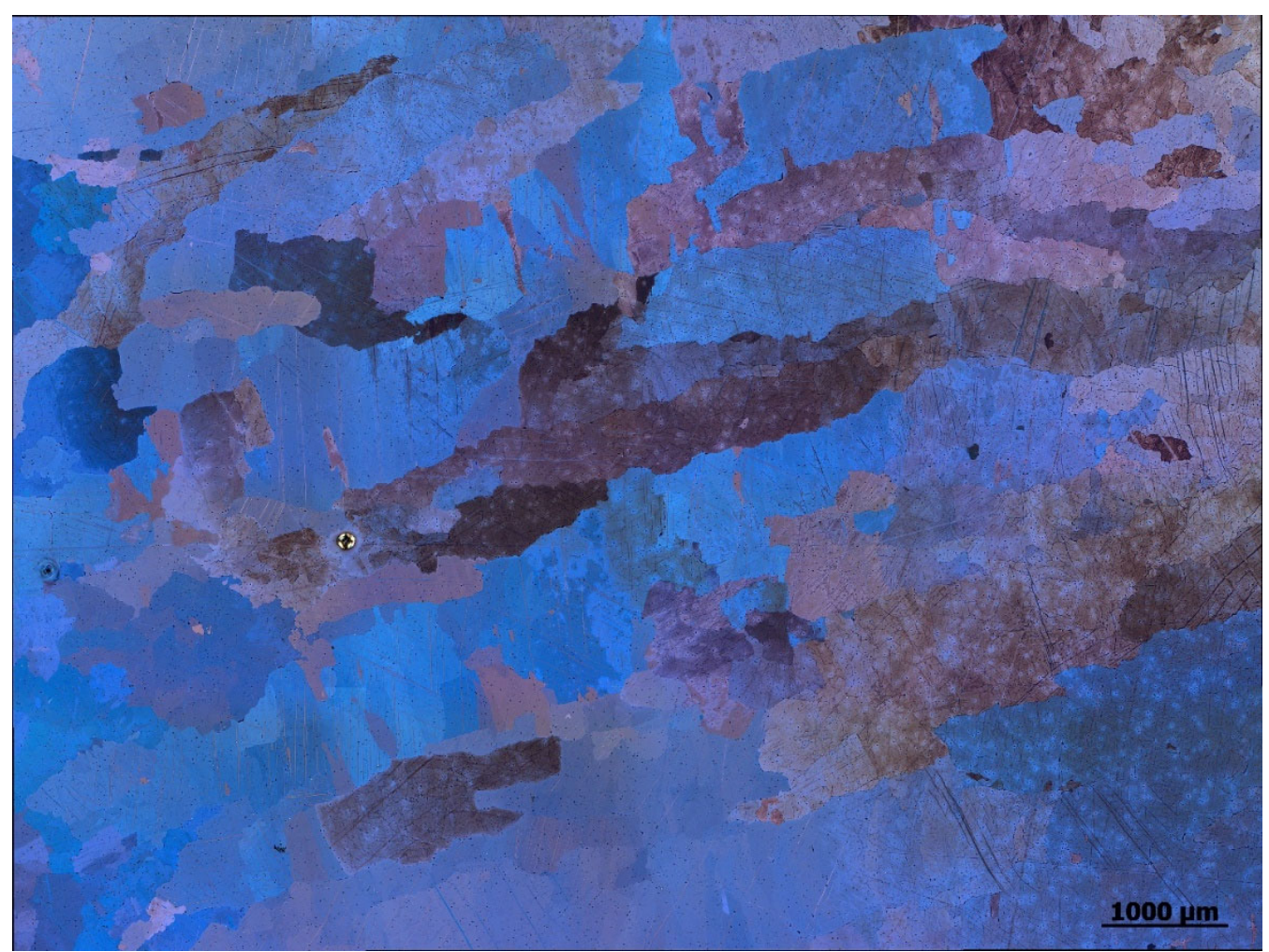

Figure 13: Montage image (each 50x) of section C2. As small pore, presumed to be due to gas evolution, is visible on the left hand side.

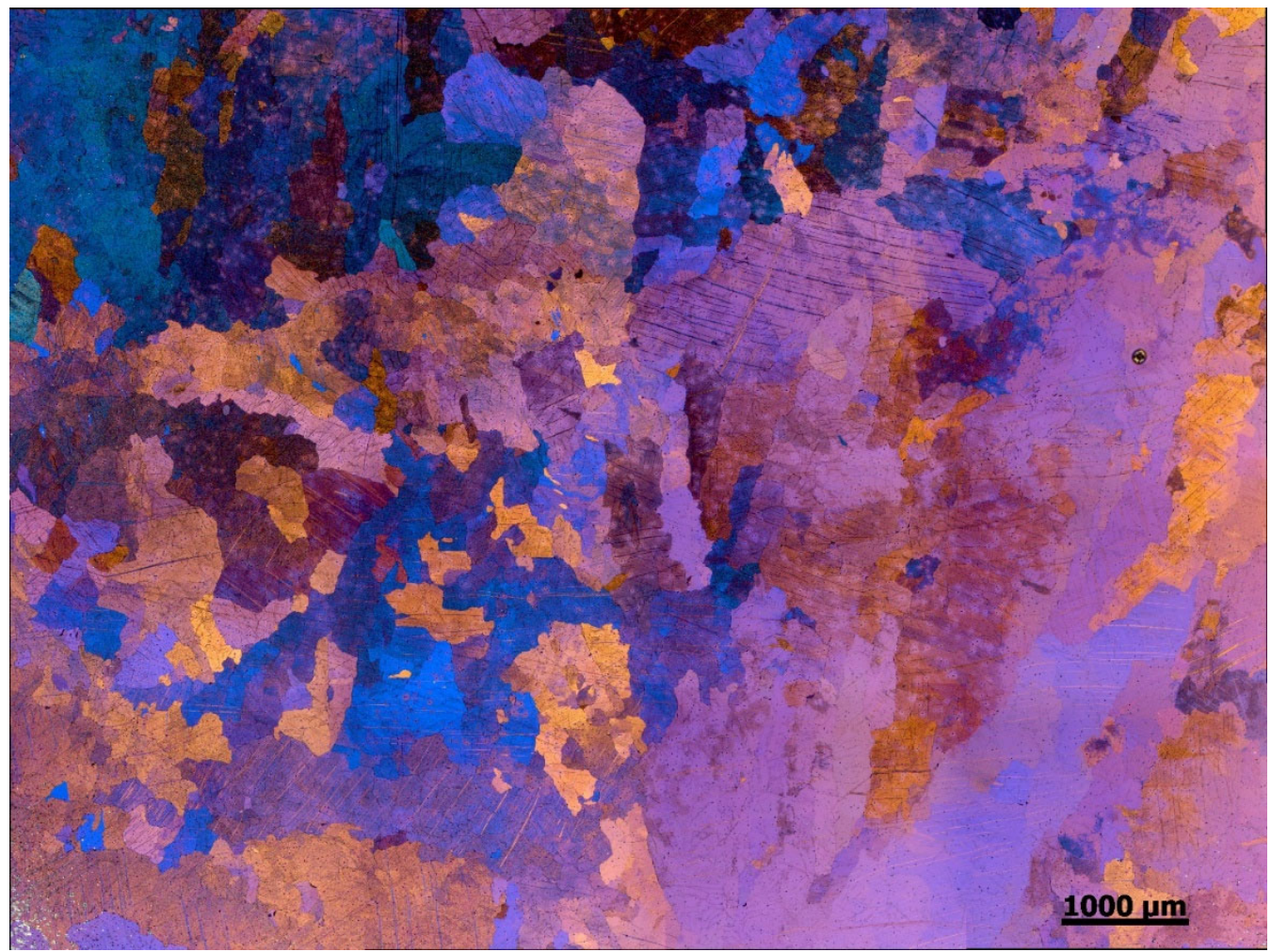

Figure 14: C3 image montage showing a combination of large and smaller grains. A small spherical pore is visible on the right hand side of the micrograph. 


\section{$\sum$ Foundry and Solidification Science Team Los Alamos National Laboratory}

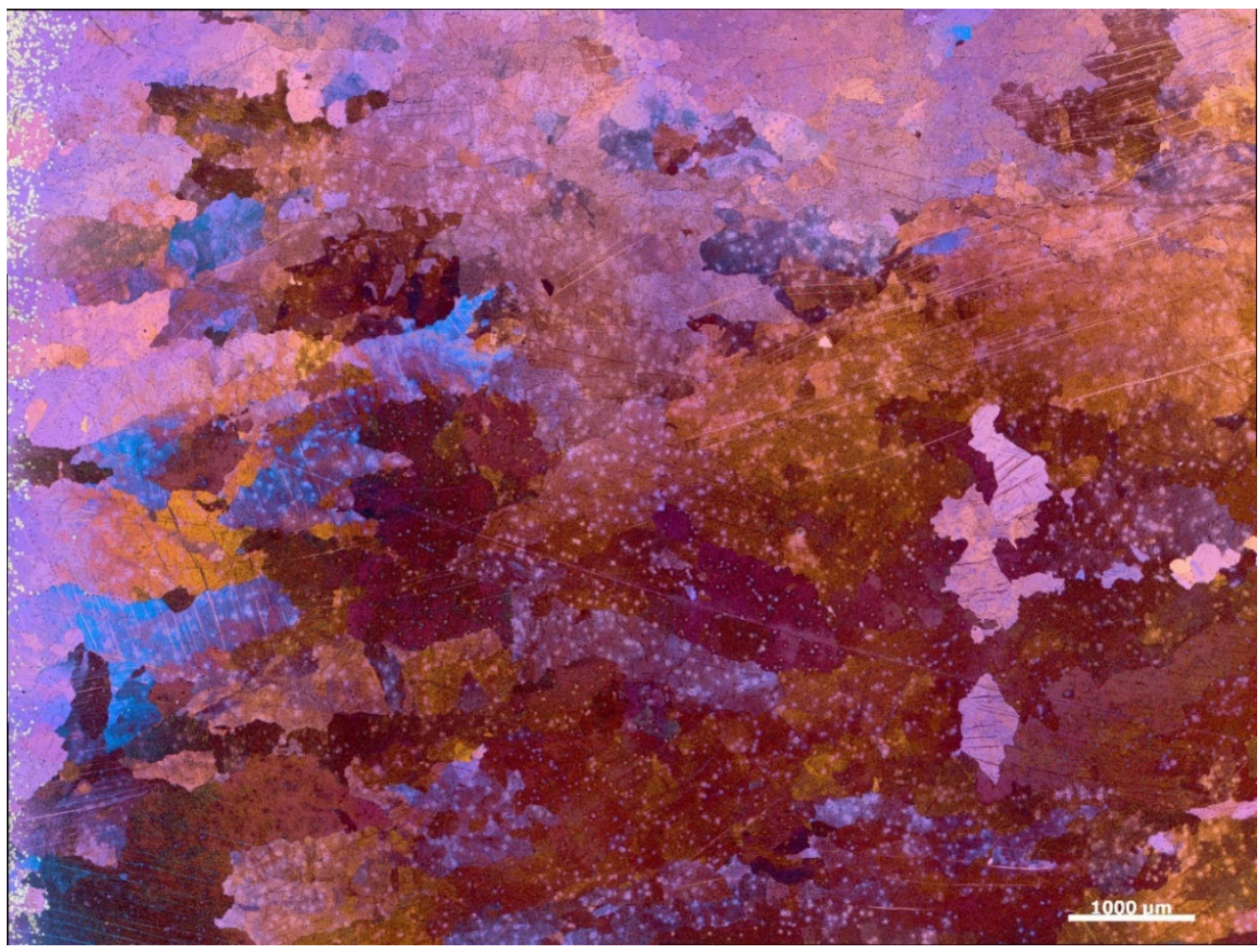

Figure 15: Image montage of section C4 showing a large grain structure.

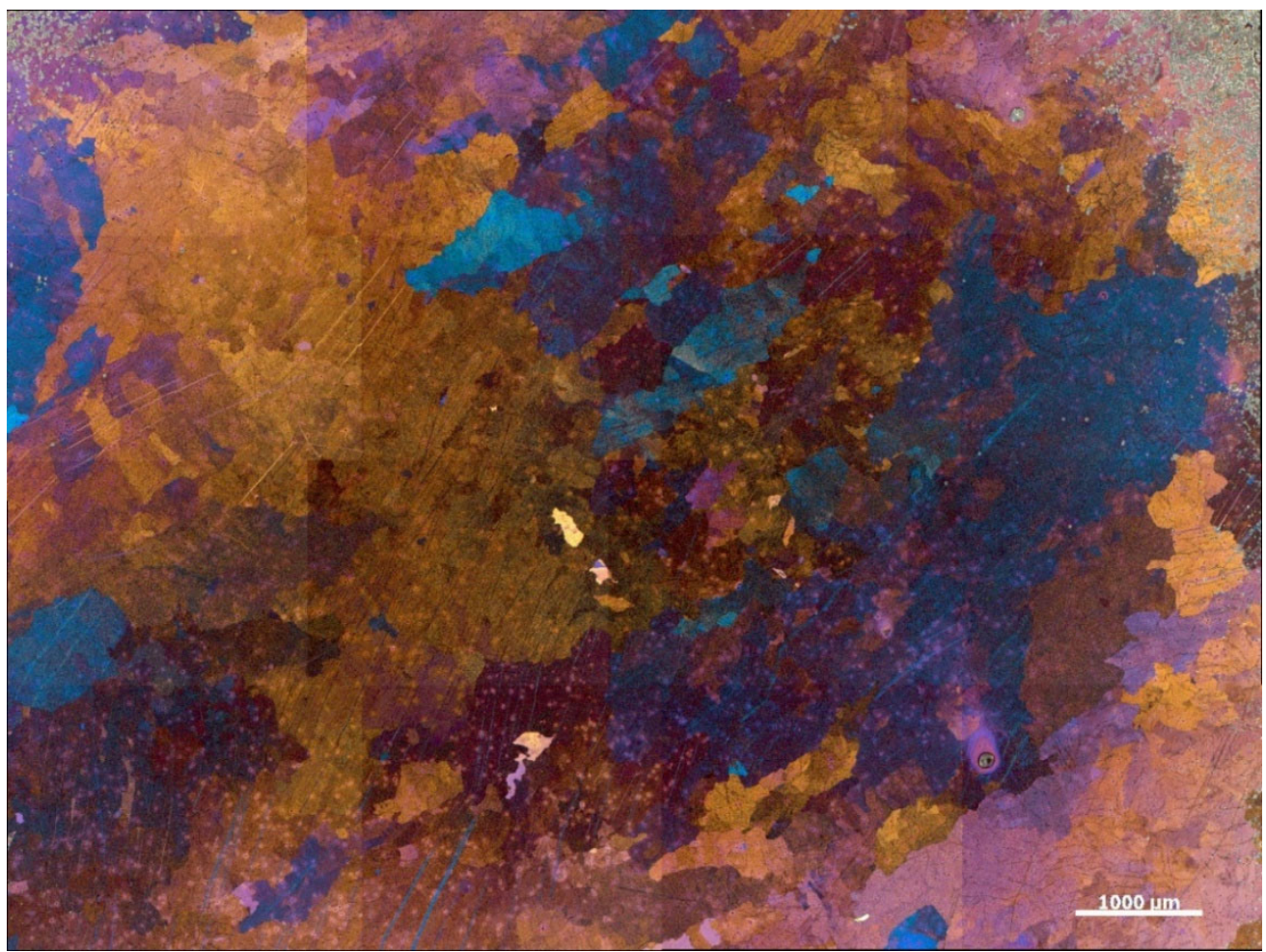

Figure 16: C5 image montage showing larger grains that do not appear to be directional. A small spherical pore is visible in the lower right hand corner of the micrograph. 


\subsection{Bulleted Summary of Findings}

- Overall, the microstructure is typical of as cast uranium with the level of carbon and other impurities measured.

- The large grain size requires large areas of consistent quality to be sampled for grain size analysis. Through CTO wall thickness, a 1D line intersects with approximately 5 to 20 grains.

- There were no indications of shrinkage porosity, but small circular voids were apparent in four of the five sections likely due to gas bubbles.

- Minor microcracking is visible at exterior surface of the casting

- $\mathrm{U}(\mathrm{CN})$ crystals are the dominant inclusion type. Oxygen-rich (with or without nitrogen and carbon) uranium inclusions are also present in large numbers.

- $\mathrm{U}(\mathrm{OCN})$ inclusions manifest with a nitrogen-rich central portion which may include oxygen and uranium carbide outer region.

- Elongated oxygen-rich second phases were found at grain boundaries in all five sections of casting PT-01.

- Total carbon content was very weakly varying or non-varying with vertical position in the casting.

\subsection{Discussion}

There are three main results to be taken from the work described above: 1.) The carbon chemistry results from Y-12 and LANL regarding early prototype microwave CTO and cylinder castings are identical, within reasonable error. 2.) The carbon chemistry does not appear to vary spatially, at least at the relatively low carbon levels (hypoeutectic) observed in PT-01. 3.) The large size and directional nature of the grains can present difficulties in making quantitative assessments, but it does allow for conclusions to be drawn regarding how the casting solidified. These three main results require some discussion of both analytical work practices as well technical notes regarding the solidification of uranium.

\subsection{Cross-site chemistry}

Some apparent differences between measurements taken at different sites precipitated the initiation of a "Carbon Round Robin" project that is separate from this current work. As part of this other project, Sigma-1 was able to compare their own carbon analysis procedure to that of $\mathrm{Y}-12 .[9,10]$ The primary difference between the two is with regards to sample cleaning. In this study, and in general, the goal within Sigma-1 is to avoid cleaning steps for chip samples by extracting them in a dry condition with a new drill bit using a mill for precision of spindle speed and placement. Doing this, the chips typically never come in contact with any lubricants and potential contamination from the bit is monitored by means of sparking or erosion. Therefore, residue deposition from cleaning steps does not need to be considered.

As should be expected, the instrumentation used to perform the measurement, if properly calibrated, should not be a major source of error. Carbon analyzers have been used across many metals industries for many years. Therefore extraction methods appear to be the most important cause of variations. Past experience at LANL, not 
associated with the work described in this report, has shown that improper sampling will lead to erroneous results. In one case study, a technician made the decision to use a cutting fluid on particularly difficult to extract chip samples. While this decision is acceptable, if the proper fluid is selected and steps are taken to clean the samples, the technician used WD-40 (a commercial all-purpose lubricant), which is not easily cleaned and renders the samples useless (false readings $>1000$ wppm $\mathrm{C}$ even after multiple cleaning steps). While this particular case study does not have any direct relevance to the sampling performed in this report, it highlights the importance of deliberate and considered actions during processing. To reiterate, despite different personnel and different (but well considered) procedures, Sigma-1's carbon analysis results matched those performed by Y-12.

\subsection{Carbon Content and Ensemble Characteristics}

Carbon in otherwise pure cast uranium has two critical morphologies and three critical size manifestations depending upon precipitation time and evolution. Large inclusions (may be multiple coalesced particles) which would have been present in the melt, isolated mid-sized crystals which nucleate in the liquid near the solidification front, and either very fine dispersion or grain boundary decoration as a result of intercellular microsegregation. The fine dispersion of carbides tend to occur in the solid state, while individual carbide particles at grain boundaries may have originated from the liquid or the solid. At hypereutectic carbon concentrations (> 180 wppm C), uranium carbide particles may be present in the initial liquid prior to solidification. These individual particles may form agglomerates which could enter the casting as large inclusions. None of these large carbides are observed in the microscopy data.

Extremely fine precipitates that are remnants of intercellular micro segregation are not counted in traditional optical microscopy analysis. It is known a priori that the data from image analysis is censored due to any number of restrictions and this is taken into account when interpreting data. For further discussion of practical carbide analysis limitations, see Imhoff et al.[11].

The weak trends in carbide particle characteristics may be the result of slightly longer residence time prior to solidification. A generally decreasing number density and generally increasing size of carbides may indicate some coarsening or differences in nucleation rate. If the liquid at the top of the casting cooled slower, then precipitation may occur at the same rate, but diffusion of carbon would grow the larger crystals at the expense of smaller crystals [12]. If there was lower undercooling, then the nucleation rate may be smaller near the upper portion of the mold. Given the same residence time, normal diffusional growth may still use the supersaturated levels of carbon, but with a smaller number of total growth centers.

\subsection{Grain Size and Shape}

Final grain size and shape are dependent upon multiple factors during casting. Castings in general may exhibit columnar growth near the mold walls and equiaxed growth once the solidification rate drops (near the center of thick cross sections). Columnar grains will tend to be elongated in the direction from the mold wall in the major direction of heat flow and especially in thin cross-section castings, the entire thickness may be made up of columnar grains. The number of grains is initially set by 
the nucleation rate of crystals from the liquid, which is undercooling dependent and heterogeneous site-limited, Figure 17(1). Growth competition between nucleated grains will act to decrease the total number of grains and therefore increase size. Some growth competition is purely geometric, such as at corners of castings where grains are guaranteed to impinge upon and therefore disrupt the growth of one another, Figure 17(2). In other instances, especially early in the growth process, very slight differences in heat flow (or mass flow) will allow one grain to grow ahead of- and halt the growth of- their neighbors, Figure 17(5). These dynamic solidification events tend to be more dependent upon the details of material chemistry (impurities), thermal boundary conditions of the mold/melt, and the geometry of the mold and not on the processing route. That said, some processing technologies may tend to favor certain conditions.

Each grain may exhibit instability of its growth front based upon thermal or solutal conditions. Slower growth speeds exhibited during traditional vacuum or newer microwave casting, are not typically prone to the formation of thermal dendrites, so discussion of these morphologies will not be expanded upon. However, growth front instability is highly sensitive to any impurities because of solute rejection (or solvent rejection in some cases) into the liquid ahead of the growing solid can lead to perturbation exaggeration at the interface.

Real materials that have some impurities, such as the uranium that is being assessed in this report, will therefore often start solidifying with smooth nearly-planar growth interfaces, Figure 17(3) which degenerate into cells, Figure 17(4). Cells may be described as finger-like growth fronts which originated as small perturbations on the surface of a planar front. Since the impurity level is still low, these cells may only rarely undergo a second morphology change to dendritic growth, Figure 17(8). Unlike dendritic solidification, cell orientation during growth is not strongly tied to crystallographic direction. In most BCC crystals (like solidifying gamma phase uranium), the main branch of a dendrite will tend to be aligned with the 001 crystallographic direction due to atom packing efficiency reasons. [13] This feature, along with the shape of the tip of the cell or dendrite, Figure 17(9), are important factors when determining what stage of instability ${ }^{1}$ is dominant. The core of each cell will be close to the tie-line composition at the liquidus and the intercellular regions, Figure 17(6) will, in the case of low impurity levels of carbon, be slightly carbon enriched. This remnant of the solidification, collections of extremely small carbide crystals, are visible in optical microscopy as a faintly gray intragranular substructure which follow the solidification boundaries. In Figure 17, these concepts are illuminated using a schematic representation.

The features of the microstructures that have been assessed represent relatively pure cast uranium and are not any sort of outlier based upon casting technology. Lower in the mold cavity, the grains appear to be highly elongated which would imply that

\footnotetext{
1 The exact definitions of growth modes can, at times, be referred to with some minor differences in features or behavior, especially at the boundaries between two clear growth morphologies. Most notably, some authors define a cell based upon growth-tip shape while others may incorporate preferential growth direction.
} 
columnar growth dominates. Near the riser (hot top or lug) region of the mold cavity, it is typical to exhibit a more equiaxed grain structure because solidification slows down, the temperatures within the melt become more isothermal, and small undercoolings can lead to new grain nucleation ahead of the otherwise columnar front. Within grains, there are indications of intercellular segregation in the form of faint subboundaries that appear to be very small precipitates.

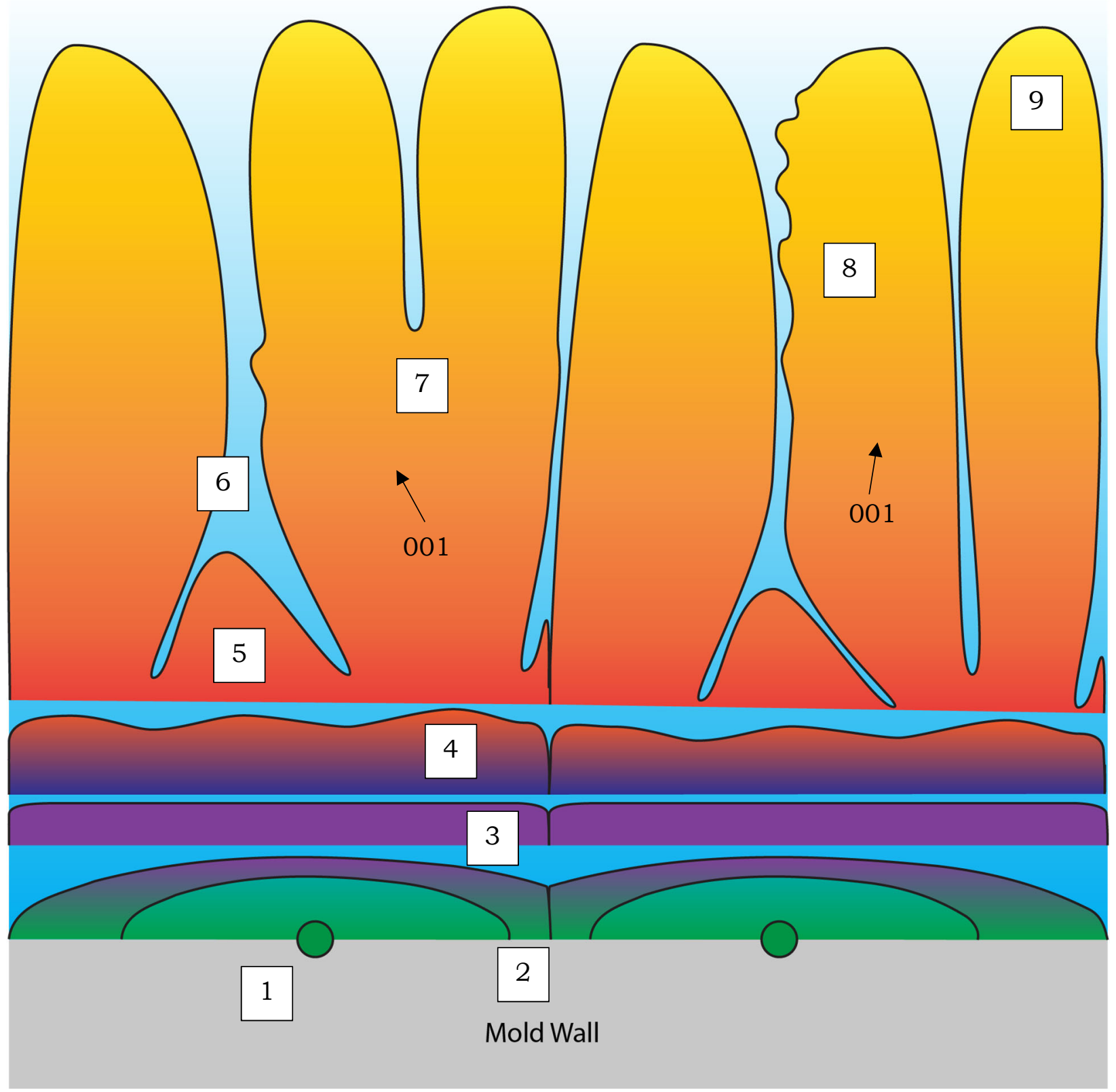

Figure 17: A schematic representation illustrating the transition from initial growth after nucleation to planar growth and interfacial instability resulting in a cellular morphology. Interfaces are drawn at key event-drive (arbitrary) times with the final result being two crystals side by side. (1) initial nucleation, (2) grain impingement, (3) planar growth (4) planar instability (5) cellular dynamic coarsening by competition (6) intercellular liquid, (7) cell bifurcation or tip splitting, (8) cellular side-branch instability with a classification of cellular dendrite, and (9) hemispherical tip of a classically growing cell. Arbitrary 001 crystallographic directions are noted for discussion. 


\subsection{Summary}

Metallography and carbon analysis by combustion methods have been conducted on castings produced using the prototype microwave casting system purchased by Y-12. The focal point of this study is the as cast PT-01 cast test object (CTO) which is the only fully intact as-cast material received at LANL. The microstructure of the casting is typical for relatively slow cooled pure uranium. There were not any large shrinkagevoids observed which indicates that the temperature profile was within the necessary processing window for production of a sound casting. Large grains relative to the casting cross section make quantitative analysis challenging. Some small and isolated gas pores were observed in most of the metallographic sections, an occasional feature of cast uranium with several possible contributing mechanisms. While the origin of these particular pores was not explored, it is not surprising, especially considering the casting is performed in a near-ambient inert gas atmosphere. For those castings with pre-existing carbon analysis measurements, results obtained at LANL have been found to match those performed previously. The standard procedures for sample extraction between Sigma-1 and Y-12 have some differences, though these differences did not seem to impact the measured values.

\subsection{Future work}

In order to qualify any material produced with a new technique, we need to assess material performance at the limits of service conditions. Therefore, LANL plans to conduct a statistically relevant experiment campaign to (1) rapidly assess the corrosion behavior in humid environments, (2) assess propensity for cracking in storage environments, and (3) collect representative materials property data with direct comparison to legacy material. These data, together with the boundingcondition testing conducted at other sites, will enable us to make an initial engineering assessment of environmental resistance of microwave material.

LANL recently initiated preliminary experiments to assess corrosion behavior in humid environments using the metallographic samples discussed in this report. A simple experimental configuration, a Petri dish humidity chamber (PDHC), was chosen because it is easy to field and replicate [14] and can be used to determine baseline corrosion rates. A schematic of the PDHC is shown in Figure 18a and a photograph of sample C2 is shown in Figure 18b. Specimens will be monitored for surface corrosion on an continual basis; photomicrographs will document corrosion progression and weight loss measurements at the conclusion of the experiment will be used to determine corrosion rates. 


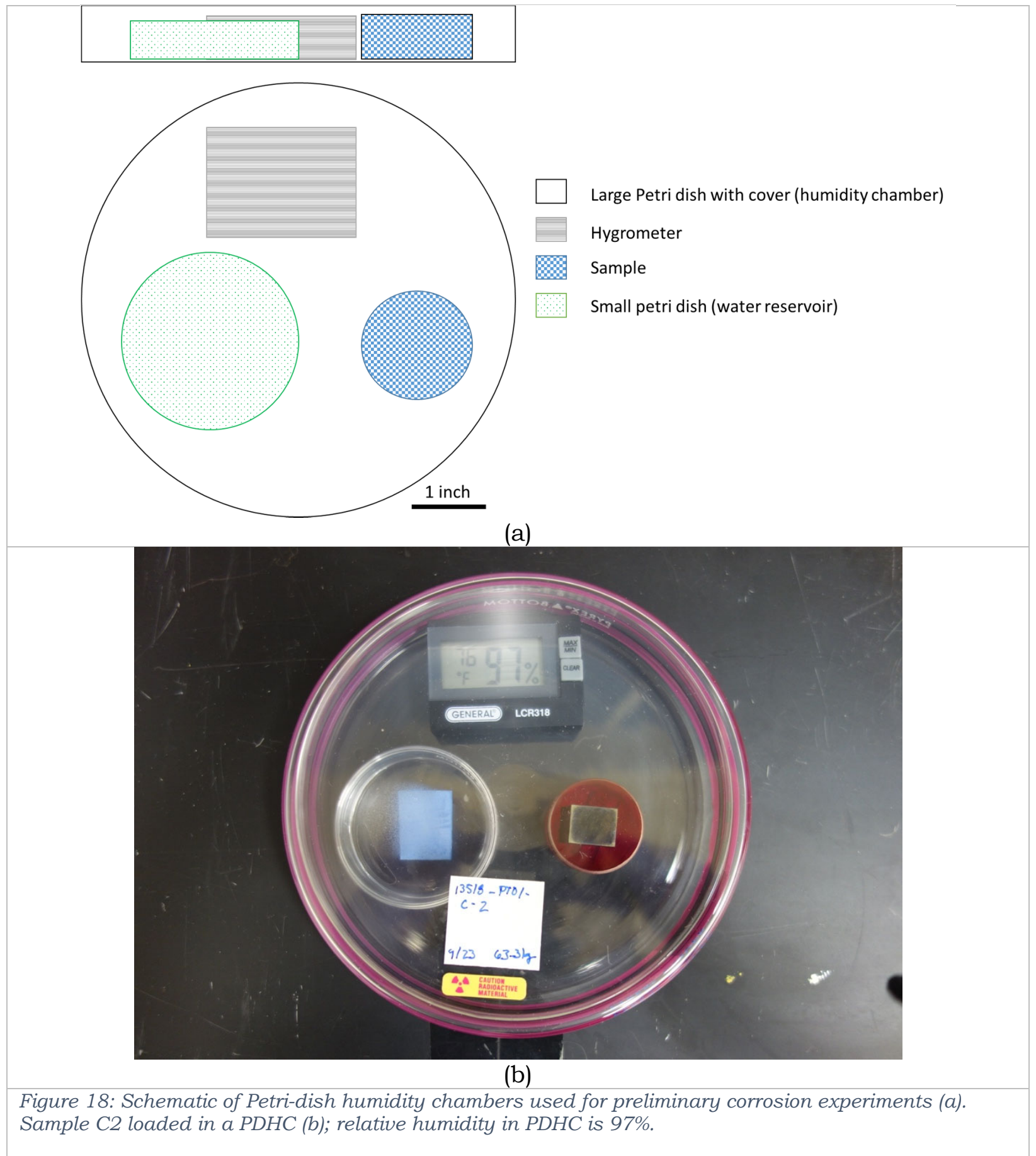

\section{Acknowledgements}

Beyond the authors of this report document, a considerable amount of effort was made by many individuals. Generally, the entire Sigma Foundry and Solidification Science team, but with special thanks to: Hunter Swenson and Jeffrey C. Robison (LANL, SIGMA-1). Additionally, the authors thank the Y-12 and Teledyne Brown staff involved in this project. 
$\sum \begin{aligned} & \text { Foundry and Solidification Science Team } \\ & \text { Los Alamos National Laboratory }\end{aligned}$

\section{References}

1 Dale E. Christenson to Mr. Brian P. Reilly, Uranium Processing Facility Project Office, October 5, 2017, Oak Ridge, Tennessee, COR-ENG-10.4.2017-759815.

2 UPF Project Management (2017), UPF Microwave Casting Technology Readiness Assessment Report for TRL-7, RP-EX-801768-A018, Rev. 0.

3 Carlton, Holly D., Golosker, Ilya V., Mycroft, Ann T. (2018) Advanced characterization of microwave melt cast uranium, Lawrence Livermore National Laboratory (LLNL), LLNL-TR752563.

4 Pearce, R.J., Whittle, I., Hilton, D.A. (1969) The oxidation of uranium in carbon dioxide and carbon monoxide: A review, J. Nucl. Mater., 33, 1-16.

5 Reiner, R.H., Holcombe, C.E. (1986) Carbon monoxide reaction with liquid uranium-niobium alloys, Oak Ridge, TN, 1986.

6 Chambers, J. M., Freeny, A and Heiberger, R. M. (1992) Analysis of variance; designed

experiments. Chapter 5 of Statistical Models in S eds J. M. Chambers and T. J. Hastie,

Wadsworth \& Brooks/Cole.

7 Miller, R. G. (1981) Simultaneous Statistical Inference. Springer.

8 Yandell, B. S. (1997) Practical Data Analysis for Designed Experiments. Chapman \& Hall.

9 Gubel, N., Degreasing and pickling of metals Rev. 1.2, Y-12 National Security Complex, Oak Ridge, TN, Dated: 03-12-2020.

10 Gubel, N., Carbon analysis using the LECO CS844 analyzer Rev. 1.1, Y-12 National Security Complex, Oak Ridge, TN, Dated: 02-13-2020.

11 Imhoff, S.D., Swenson, H., Luitjohan, K.E., Kral, G.A., Forsyth, R.T. (2019) FY19 Report: Effect of filtration on inclusion carbon reduction, Los Alamos National Laboratory, LA-UR-1932038.

12 I.M. Lifshitz, V.V. Slyozov (1961) The kinetics of precipitation from supersaturated solid solutions, J. Phys. Chem. Solids 19, 35-50.

13 Dantzig, J.A., Rappaz, M. (2009) Solidification, EPFL Press, pg. 289.

$14 \mathrm{Li}, \mathrm{S}$., Hihara, L. (2010) Atmospheric corrosion initiation on steel from predeposited $\mathrm{NaCl}$ salt particles in high humidity atmospheres, Corrosion Engineering Science and Technology 445(1), 49-56. 